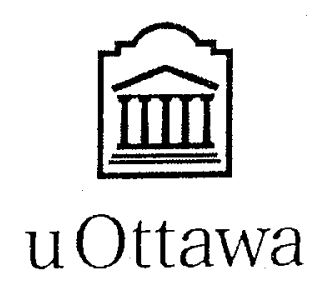

l.'Université canadicune Canada's university 
FACULTÉ DES ÉTUDES SUPÉRIEURES ET POSTOCTORALES
uOttawa

I.'Université canadienne

Canada's universily
FACULTY OF GRADUATE AND

POSDOCTORAL STUDIES

\section{Li Zhang}

AUTEUR DE LA THESE I AUTHOR OF THESIS

\section{M.Sc. (Human Kinetics)}

GRADE IDEGREE

Department of Human Kinetics

FACULTE, ECOLE, DÉPARTEMENT I FACULTY, SCHOOL, DEPARTMENT

Locomotor Adjustments made by Toddlers while Stepping over Obstacles

TITRE DE LA THESE / TITLE OF THESIS

Heidi Sveistrup

DIRECTEUR (DIRECTRICE) DE LA THESE / THESIS SUPERVISOR

Gordon Robertson

CO-DIRECTEUR (CO-DIRECTRICE) DE LA THESE / THESIS CO-SUPERVISOR

EXAMINATEURS (EXAMINATRICES) DE LA THĖSE / THESIS EXAMINERS

Jing Xian Li

Yves Lajoie

Gary W. Slater

Le Doyen de la Faculte des études superieures et postdoctorales / Dean of the Faculty of Graduate and Postdoctoral Studies 


\title{
LOCOMOTOR ADJUSTMENTS MADE BY TODDLERS WHILE STEPPING OVER OBSTACLES
}

\author{
School of Human Kinetics \\ Faculty of Health Sciences \\ University of Ottawa
}

(C) Li Zhang, Ottawa, Canada, 2008 


$\begin{array}{ll}\begin{array}{l}\text { Library and } \\ \text { Archives Canada }\end{array} & \begin{array}{l}\text { Bibliothèque et } \\ \text { Archives Canada }\end{array} \\ \begin{array}{l}\text { Published Heritage } \\ \text { Branch }\end{array} & \begin{array}{l}\text { Direction du } \\ \text { Patrimoine de l'édition }\end{array} \\ \begin{array}{l}\text { 395 Wellington Street } \\ \text { Ottawa ON K1A 0N4 } \\ \text { Canada }\end{array} & \begin{array}{l}\text { 395, rue Wellington } \\ \text { Ottawa ON K1A 0N4 } \\ \text { Canada }\end{array}\end{array}$

Your file Votre référence ISBN: 978-0-494-50942-5 Our file Notre référence ISBN: 978-0-494-50942-5

NOTICE:

The author has granted a nonexclusive license allowing Library and Archives Canada to reproduce, publish, archive, preserve, conserve, communicate to the public by telecommunication or on the Internet, loan, distribute and sell theses worldwide, for commercial or noncommercial purposes, in microform, paper, electronic and/or any other formats.

The author retains copyright ownership and moral rights in this thesis. Neither the thesis nor substantial extracts from it may be printed or otherwise reproduced without the author's permission.
AVIS:

L'auteur a accordé une licence non exclusive permettant à la Bibliothèque et Archives Canada de reproduire, publier, archiver, sauvegarder, conserver, transmettre au public par télécommunication ou par l'Internet, prêter, distribuer et vendre des thèses partout dans le monde, à des fins commerciales ou autres, sur support microforme, papier, électronique et/ou autres formats.

L'auteur conserve la propriété du droit d'auteur et des droits moraux qui protège cette thèse. $\mathrm{Ni}$ la thèse ni des extraits substantiels de celle-ci ne doivent être imprimés ou autrement reproduits sans son autorisation.
In compliance with the Canadian Privacy Act some supporting forms may have been removed from this thesis.

While these forms may be included in the document page count, their removal does not represent any loss of content from the thesis.
Conformément à la loi canadienne sur la protection de la vie privée, quelques formulaires secondaires ont été enlevés de cette thèse.

Bien que ces formulaires aient inclus dans la pagination, il n'y aura aucun contenu manquant.

\section{Canada}




\section{Acknowledgements}

I wish to express my deepest gratitude to my supervisor, Professor Heidi Sveistrup, Ph.D., for her invaluable trust and support throughout the study.

I also would like thank my other advisor, Professor Gorden Robertson, Ph.D., without his technical guidance this work would've never been completed.

Without the participation of the toddlers and their parents as well as the Aladin Childcare Center this project would not have been possible.

This thesis is dedicated to my beloved son, Felix who inspired me to explore the insight of motor development and my husband, Huan who provided tremendous help through my academic pursuit. 


\section{TABLE OF CONTENTS}
ABSTRACT.
INTRODUCTION
STUDY OBJECTIVE

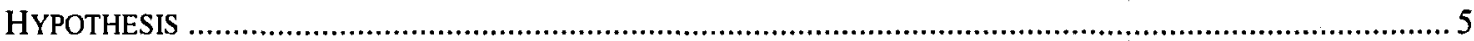

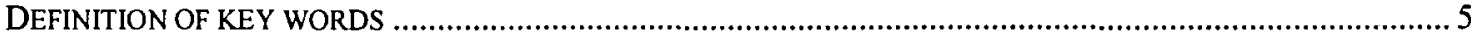

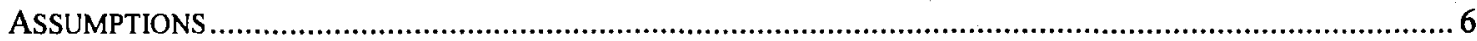

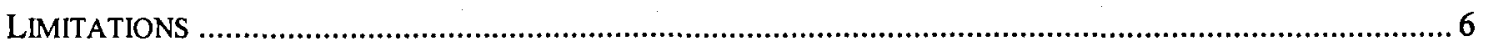

1

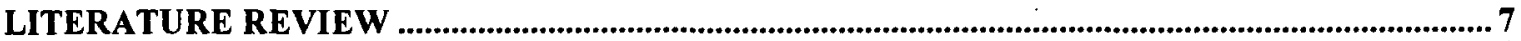

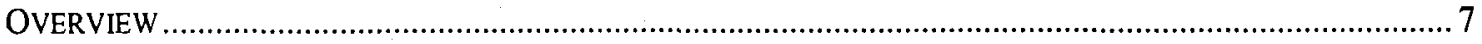

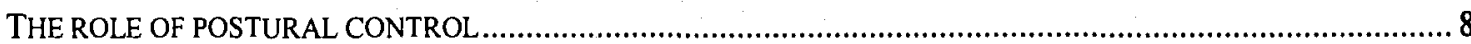

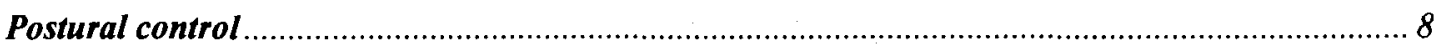

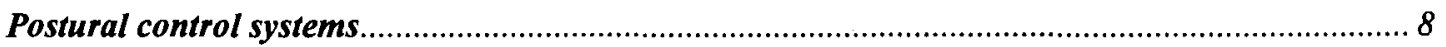

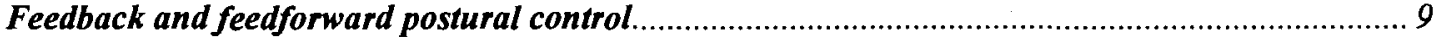

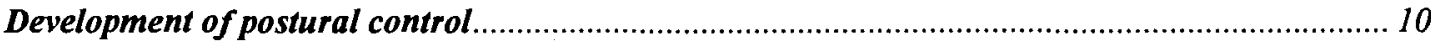

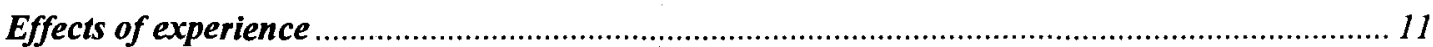

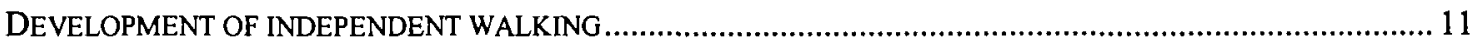

A model of gait development .......................................................................................................... 11

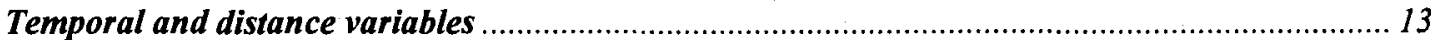

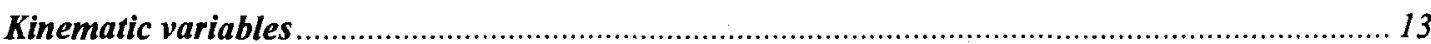

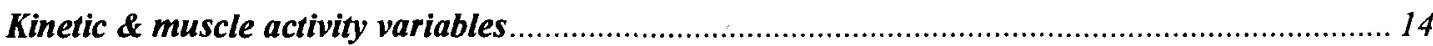

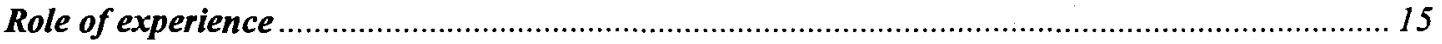

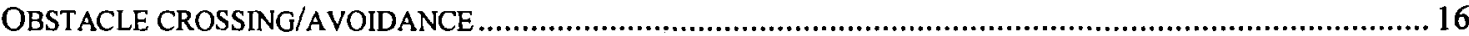

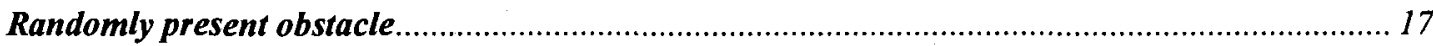

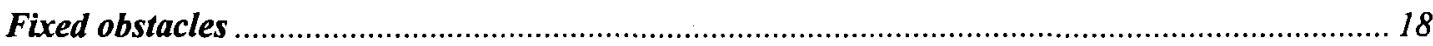

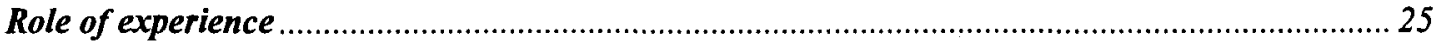

SUMMARY

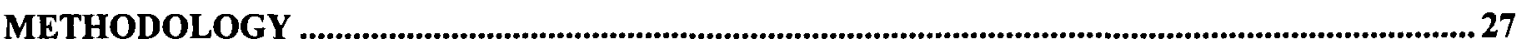

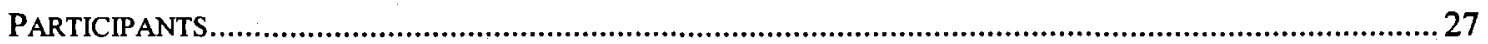

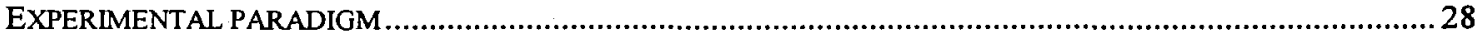

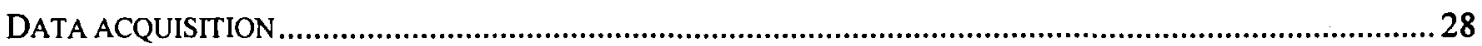

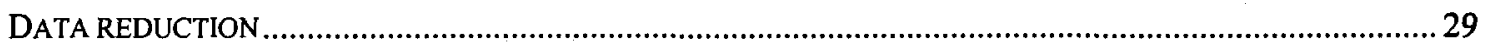

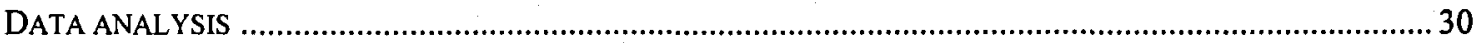

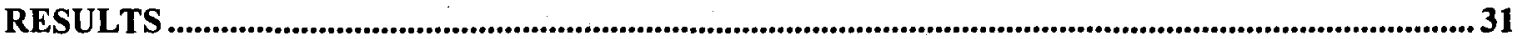




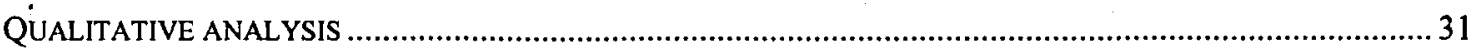

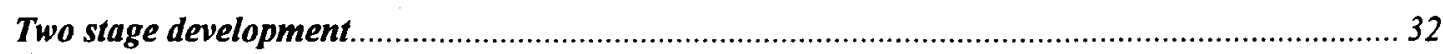

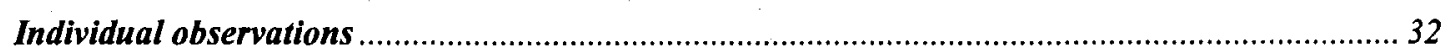

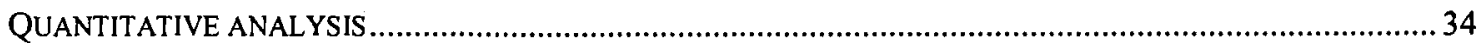

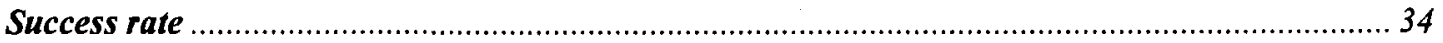

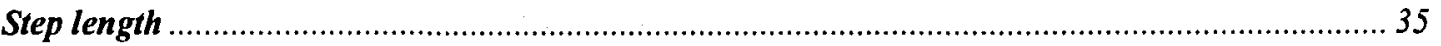

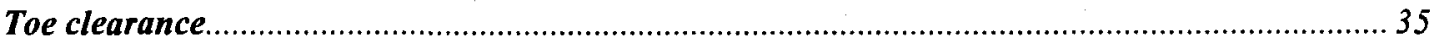

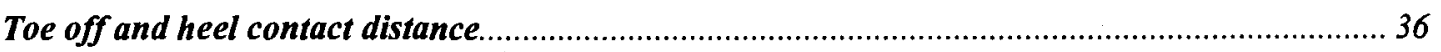

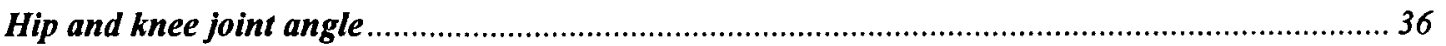

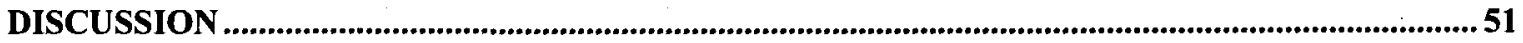

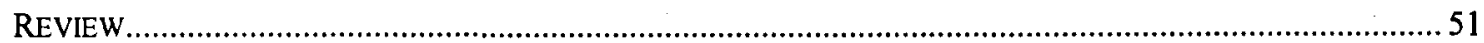

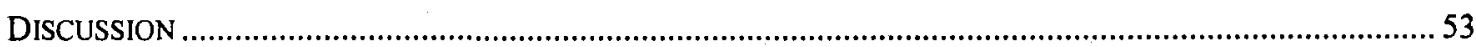

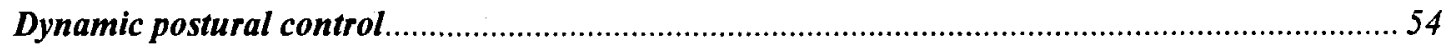

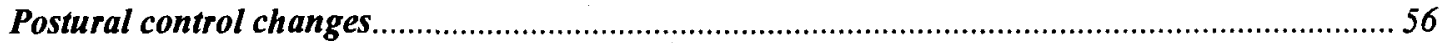

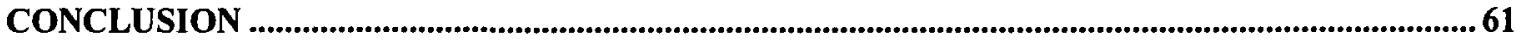

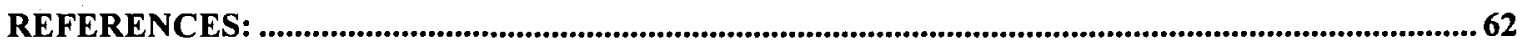

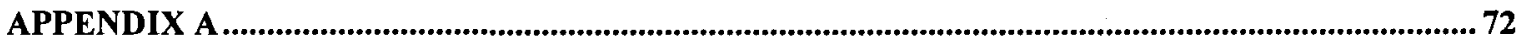

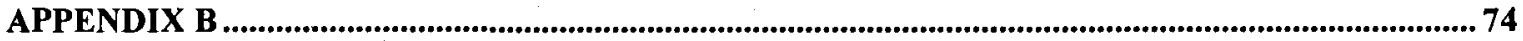

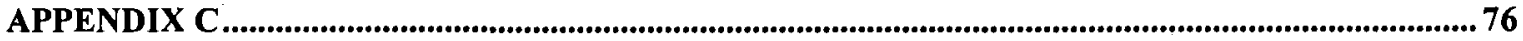

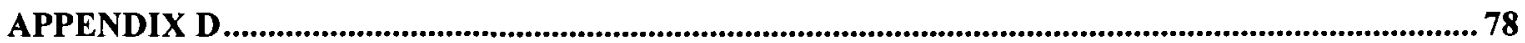




\section{List of Figures}

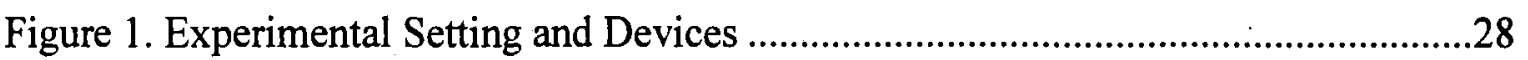

Figure 2. Dependent Variables ......................................................................................30

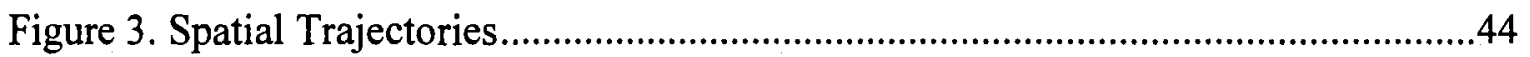

Figure 4. Step Length vs. Month of Walking ...............................................................46

Figure 5. Leading and Trailing Toe Clearance..............................................................4

Figure 6. Toe and Heel Distance ................................................................................

Figure 7. Feed-forward and Feedback Postural Adjustment .............................................52

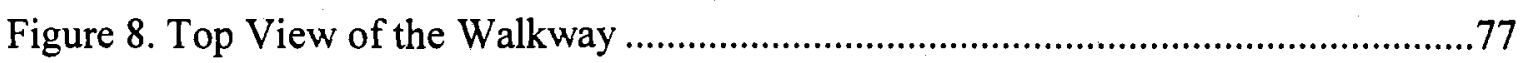




\section{List of Tables}

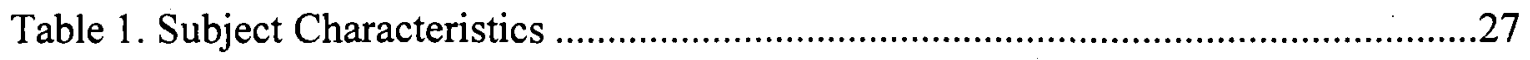

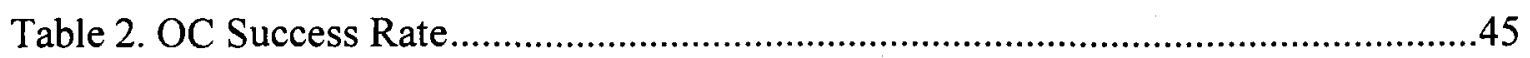

Table 3. Leading and Trailing Toe and Heel Distance to Obstacle ................................49

Table 4. Knee Joint Flexion and Hip Joint Extension: Pairwise Comparisons .................50

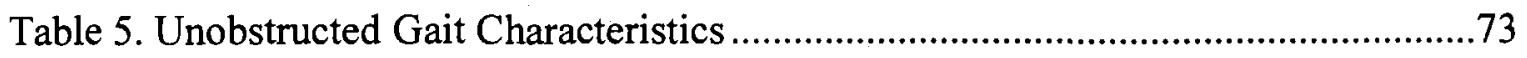

Table 6. Time-distance Parameters....................................................................... 75 


\begin{abstract}
Temporal, kinematic and kinetic patterns of independent walking (IW) in toddlers have been characterized in various studies with postural control identified as a critical component influencing the coordination between gait mechanisms to maintain a dynamic equilibrium. Variations in parameters across development indicate that toddlers possess more adult-like integration capabilities in locomotor control after 4 to 5 months of independent walking (Bril \& Brenière, 1989, 1990, 1991, 1992). However, whether this integration would be influenced in a subtle complex locomotor task, obstacle crossing remains unknown. This study examined locomotor modulation during obstacle crossing in eight healthy toddlers (six males and two females; mean height $=80.6 \mathrm{~cm}$ ) with 1 to 8 months IW experience. At least five trials of unobstructed walking (UW) and obstacle crossing (OC) were recorded using a Vicon motion analysis system (Oxford Metric Ltd, Oxford, UK). Lower extremity trajectories during unobstructed walking and while crossing a visible fixed obstacle were analyzed (Visual3D Motion Analysis System, C-motion Inc, Rockville, Maryland. US). As months of walking increased, segmental trajectories over the obstacle appeared to be more consistent. With 4- to 5-month IW toddlers displaying more adult-like OC patterns. This tendency was reflected by less variability of leading and trailing toe-to-obstacle distance (TD) and crossing stride length (SL). As IW experience increased, safety and stability were improved as the leading and trailing toe clearance distance over the obstacle (TC), knee flexion, crossing step length (SL), and heel distance (HD) increased accordingly. The most dramatic changes of these variables occurred after 4 to 5 months IW. In addition, success rate increased as months of walking suggested that better integrated postural control was achieved.
\end{abstract}




\section{CHAPTER I}

\section{Introduction}

Development of gait in humans has been investigated over developmental stages from various perspectives of view. Forssberg (1985) speculated that the maturation of gait corresponds to the maturation of the central nervous system (CNS) and neural pathways. However, Thelen (1985) and Ulrich (1989) argued that the development of motor behavior is influenced by a range of factors. These authors use the "dynamical systems theory" to understand development and emphasize that the modulation of locomotion components is organized in a group of "nonlinear, complex and open systems". This theoretical framework implies that constantly changing motor behaviors reflect the influence of environmental contexts and the development of the children. Bril and Breniere (1989, 1991 \& 1992) systematically studied the kinematics, kinetics and muscle activity during independent walking, under different conditions. Their data support the approach of Thelen and Ulrich suggesting that development is nonlinear. Specifically, Bril and colleagues state that even if most components contributing to upright bipedal locomotion have been well developed, without integration of the necessary components of postural control, it is impossible to perform dynamic equilibrium. Moreover, dynamical balance control is one of the fundamental locomotion skills. Regardless of the environment encountered, for example, unobstructed pathway, or cluttered terrains, postural control during movement is required to complete the locomotor tasks without endangering ourselves.

In real world surroundings, stepping over obstacles is inevitable for both adults and children. In the newly independent walkers, a critical objective for such a locomotor task is to avoid tripping. Increasing knee flexion while limiting changes in hip joint rotation is one of the key strategies exploited by adults for clearing considerably high obstacles and producing a safe margin for the foot to cross over the obstacle (McFadyen \& Winter 1991; Patla \& Prentice, 1995). In the adult, this "margin over obstacles", called toe clearance, is always adequately high $(10 \pm 2 \mathrm{~cm})$ allowing continuous transition over the obstacles. The relatively large toe clearance over an obstacle compared to toe clearance over the ground 
during unobstructed walking indicates that energy economy is traded for safety (Patla \& Rietdyk, 1993; Rietdyk \& Patla, 1994). Similarly, hip elevation, which assists in lifting the swing limb up to clear obstacles, disturbs the mass of the whole upper body. This is also contrary to principles of energy economy (Patla, Prentice, \& Gobbi, 1996). These strategies imply that, in obstacle crossing, fall prevention guides the motor patterns used.

Children are in constant physical development. For normal walking, a two-stage motor development was proposed (Bril \& Breniere, 1990). The first stage of independent walking emerges around the age of 10 to 12 months and ends around the age of 16-20 months. During this stage, the components contributing to upright bipedal locomotion integrate to become intact ensembles (Fentress, 1984). This is the most critical stage in gait development. The most dramatic change of several parameters including velocity, double support duration, step length and width, occurs during the first 4 to 6 months of independent walking (Bril \& Breneire, 1989, 1991, 1992). Between the ages of 1.5 to 6 years, the second stage of gait development takes place. During this period, the integration of motor components improves providing postural control during a dynamic task. Until 7 to 8 years of age, children have not achieved mature gait as demonstrated by the discrepancy between their gait patterns and those of adults.

From the perspective of correlations in accordance with the external environment and self-orientation, gait development can also be considered as a two stage process. From 9 to 10 months to 4 to 6 years of age, children perceive their orientation of the external environment by referencing themselves either static or dynamic i.e. egocentric frame (Piaget, 1971). The transition period lasts 1-2 years, during which the egocentric strategy of mapping themselves is gradually replaced with the exocentric strategy. After 9 to 10 years of age, children are able to map themselves with the reference to static objects in the external environment (Piaget, 1971).

Based on the stages of independent walking development, it appears that the task of crossing over obstacles is a great physical challenge for children younger than 7 to 8 years of age (Pryde et al., 1997). The necessary components for obstacle avoidance continue to develop in this period. After 10 years of age, although most kinematic patterns are not 
different than those displayed by adults, certain differences in frontal plane limb displacement patterns remain (Pryde et al., 1997). Specifically, children (10.3 \pm 1.5 years) make medial-lateral adjustments immediately in front of the obstacle whereas adults adjust their head, trunk and limb positions together with the center of mass well ahead of the obstacle (Vallis \& McFadyen, 2005).

The task of obstacle crossing forces toddlers to exploit compromised strategies to elicit a sufficient margin to pass over the obstacle without tripping. A preliminary study (Patla, Prentice \& Gobbi, 1996) examined four 14 to 30 month old toddlers in an obstacle avoidance task. They reported low success rates in going over the obstacle, greater values of toe clearance compared to that in unobstructed walking, greater contributions of hip hiking to swing limb clearance than what observed in adults, significant inter-trial variance, and toe-off distance to the obstacle. These are good indicators of postural instability. While most of the components contribute to walking are functional long before walking, the acquisition of bipedal locomotion does not occur in parallel. Lack of postural control caused by under developed and incomplete integration of neurosensorimusculoskeletal system and the toddlers' inexperience of crossing over obstacles prevents them from successfully completing the action every time.

Importantly, the ability to cope with a cluttered terrain is one of the essential abilities toddlers require. Although various aspects of gait development in children have been investigated, many gait development parameters remain uncharacterized. Moreover, gaitrelated tasks including obstacle crossing and level changing (e.g. stair and ramp ascent or descent) are significant skills necessary for socialization and independence.

\section{Study objective}

This study explored the kinematics of obstacle crossing in toddlers during the early periods of independent walking. Kinematic parameters were used to compare early obstacle crossing patterns over the first 8 months of independent walking as well as to obstacle crossing patterns reported for older children and adults.

The purpose of this study was threefold, 
1. describe the kinematics of how toddlers step over fixed, visible obstacles in the early (i.e. between 1 and 8 months) period of independent walking;

2. compare the kinematic parameters obtained from obstacle crossing trials with the same set of parameters displayed by the same toddlers in normal walking; and,

3. compare the kinematic parameters obtained from this study with the same set of parameters displayed by adults reported in previous obstacle crossing studies.

Through these comparisons, the special characteristics of toddler obstacle crossing were highlighted and the importance of integration of postural control within a dynamic task was explored.

\section{Hypothesis}

Specifically, we hypothesized that

1. compared with unobstructed trials, toddlers would decrease the length of the step crossing an obstacle;

2. compared to unobstructed walking, knee flexion of the leading limb will be significantly greater when stepping over an obstacle;

3. toddlers will produce greater toe clearance over an obstacle compared to that of adults as reported previously in the literature; and

4. toe clearance over an obstacle will decrease from 1 month to 8 months of independent walking.

\section{Definition of key words}


Obstacle crossing: a locomotor task indicates the process of going over the obstacles, which includes preparation, stepping over and landing phases.

Toddler: Children with between 1 and 8 months of independent walking experience.

\section{Assumptions}

1. Assumption of walking.

Walking is assumed to be a bilaterally symmetric planar movement.

2. Assumption of n-link segment models

This assumption states that the inertial properties of the various segments are constant. It was also assumed that skin movements did not alter the position of the body markers with respect to the anatomical land markers which they overlay.

\section{Limitations}

1. The displacement of reflective markers will affect the accuracy of measurement of body motion.

2. Small sample size might cause a type II error in statistical analysis. 


\section{CHAPTER II}

\section{Literature Review}

\section{Overview}

Various experimental manipulations have been used to study human movement, including gait, and the relationships between various components that influence task performance. Models of motor development, including those specifically related to gait, have become more clarified and systematic.

Opposing theories have proposed that gait development is either hierarchical or heterarchical. Forssberg (1985) a supporter of the hierarchical approach suggested that central neural system development is the primary contributor to gait development and those other factors have little influence. In contrast, Thelen (1986) has proposed that postural control and muscle strength were among the key factors limiting and/or facilitating the development of gait developing, Partially based on Thelen's research, Ulrich (1989) suggested a heterarchical approach where multiple factors within the human system all impact locomotor development.

Although muscle strength is important for the acquisition of upright stance, it is no longer a development rate limiter for gait development around age of 10 to 12 months. However, postural control, a second factor identified by Thelen (1986) as a rate limiter for locomotion, is ontogenetically adjusted to the motor task across the life span (Assaiante, Thomachot \& Aurenty, 1993; Breniere \& Bril, 1989). Assaiante (1995) developed a four stage postural control model that emphasizes the importance of both static and dynamic postural control to upright bipedal locomotion.

To understand gait development, in particular, obstacle crossing tasks, relevant literature on posture control, development of unobstructed gait, and obstacle crossing/avoidance is reviewed. The key factors influencing gait development are summarized with the focus on key kinematic, kinetic and muscle activity variables reflecting 
patterns of locomotion exhibited by healthy young adults, older adults, and children in unobstructed conditions as well as during obstacle crossing tasks.

\section{The role of postural control}

\section{Postural control}

Postural control requires maintaining the projection of the center of body mass within the support base. In order to minimizing deflections of the body from a desirable orientation, corrective movements are used to keep the projection of the centre of mass within the support base.

The principle of postural control is the balance of safety and energy economy, which is locomotor context-dependent and adaptable to the specific balance demands (Nashner, 2001).

\section{Postural control systems}

Postural control is the integration of multiple components including the nervous system, sensory systems, and musculoskeletal structure. The integration of these components continues to evolve through childhood (Sutherland, 1997).

The nervous system, as an autonomous system, is functional long before the maturation of individual sensory systems. It has two major components: central neural system (CNS) and peripheral neural system. The CNS is conceived as a system devoted to information processing, where an appropriate motor output is computed in response to sensory input.

As receptors perceive both external and internal inputs and then subsequently transfer them to the CNS via afferent pathways, the sensory system offers information with respect to its own state and relevant surroundings. The sensory system consists of visual, vestibular, and somatosensory systems.

Vision influences balance by triggering muscle activation required for postural corrections (Brandt et al., 1986). Peripheral vision is primarily used as a general spatial 
orientation system and has great influence on postural control (Lee \& Aronson, 1974). Visual acuity established at age of 9 to 24 months is critical to postural control (Paulus et al., 1984).

The vestibular system functions through the detection of acceleration and prevents us from falling while moving vigorously. The vestibulo-ocular reflex (VOR) helps stabilize the head and the body (Baloh et al., 1993). As part of VOR, nystagmus in response to angular accelerations of the head is mature within the first few months of life (Ornitz, 1983).

Somatosensory inputs provide information about joint position and whether the body is moving, with what level of effort, where the various parts of the body are located in relation to each other and in relation to the physical world, what changes occur in muscle length, force production, as well as tendon tension changes.

\section{Feedback and feedforward postural control}

Two mechanisms of postural control have been identified based on postural control studies with adults, feedback and feedforward. Feedback postural control is a sequence of reactive, compensatory movements occurring immediately after unexpected changes in the external conditions (Nashner \& Woollacott, 1979). This is also referred to as reactive postural control. Feedforward postural control involves appropriate anticipatory adjustments and is also referred to as anticipatory postural control.

Postural adjustments depend on the expectation of an external disturbance. To respond to an unexpected disturbance, e.g. loss of balance, compensatory postural adjustments are exploited in the feedback fashion. In contrast, if the disturbance can be predicted or is expected, postural control is accomplished by exploiting anticipatory postural adjustments prior to occurrence of disturbance. This results in counteracting the predicted disequilibrium (Aruin \& Latash, 1995; Bouisset \& Zattara, 1981). Both mechanisms are essential to the adults' postural repertoire and contribute to movement efficiency (Aruin \& Latash, 1995; von Hosfsten, 1993).

Unless unanticipated changes occur, adults accomplish locomotor tasks in the frame of feedforward postural control. In contrast, toddlers use spontaneous postural control 
mostly in response to external forces, gravity and transiently disturbing actions such as body sway. Berstein (1967) suggested that reactive postural control is first exploited by children and gradually becomes less important as anticipatory control is gained.

\section{Development of postural control}

Efficient postural control is scaled by assurance of safety and its energy cost (Chen et al., 1991; Patla et al., 1991; Chou et al., 1997). Postural control is context-dependent and is modified by combining strategies of different magnitudes and temporal relations to produce different postural responses (Horak \& Nashner, 1986). Postural control is gained through experience and, in other words, improvements occur over time/development.

An ontogenetic four-stage-defined model proposed by Assaiante \& Amblard (1995) elaborates relationships between the head, upper body and lower extremities of humans. The developmental model reflects how two approaches for organizations of basic postural control, descending and ascending, interact with two principles of joint articulation, "en-bloc and articulated operation", at each stage. Descending mode of postural control is based on head orientation providing movement references. On the other hand, ascending mode is stimulated by proprioceptive and cutaneous inputs transferred by effectors. The switch from egocentric to exocentric mode was also ontogenetically depicted by Grasso and his colleagues (1997).

During the first stage, birth to the emergence of upright stance, maturation and integration are emphasized. This process enables infants to exploit the descending temporal organization of unperturbed postural control associated with an articulated operation of the head-trunk unit. The following period extends to the age of 6 years and is characterized by changes in the postural control approach. Specifically, an ascending organization emerges that is associated with an "en bloc" mode of head-trunk operation. During the third stage extending from 7 years of age to later childhood, most of the motor components are mature and integrated. The period is characterized by descending postural control with articulated head-trunk coordination. The fourth and final stage lasts through adulthood and is characterized primarily by one feature, selective control of the degree of freedom at the neck. This control ensures that the adult optimizes the strategy used as a function of the situation 
and/or task. According to this model, we could find that the strategies of postural control vary ontogenetically as the degree of motor system maturation allows more sophisticated integration to occur and that ultimately ensures more flexible adaptations to environmental constraints.

\section{Effects of experience}

It has been demonstrated that individuals can organize different postural movements by combining strategies of different magnitudes and temporal relations that are influenced by the subject's recent experience (Horak \& Nashner 1986). Moreover, the appropriate postural adjustments are gained through experience. Witherington and colleagues (2002) found that both the consistency with which infants employ anticipatory postural adjustments in support of pulling behavior and the temporal specificity of their anticipatory activity progressively improved between 10 and 17 months. Muscle activity of 34 children, able to stand without support, was recorded as the children intended to open a drawer against resistant forces applied to the drawer. More specifically, anticipatory muscle activities were inconsistent in the 10 to 11 month olds whereas by 16 to 17 months, temporally specific anticipatory adjustments began to predominate. The functional outcome of the difference in postural muscle activity was that less than one in three children with age of 10 to 11 months initiated pulling within $240 \mathrm{msec}$ in contrast greater than half children with age of 16 to 17 months. Thus, feed-forward postural control consolidated with age in early childhood.

\section{Development of independent walking}

The development of gait has been the focus of research since the early to middle part of the last century (McGraw, 1932, 1943; Gesell, 1945). Gait maturation begins at very early stages of human life. Reflexes resembling the early stage of independent walking, including kicking, stepping and walking, exhibit properties of interaction between motor elements, even prior to the onset of upright stance. Motor elements begin to develop early in fetal development even though their development progression is non-linear.

\section{A model of gait development}


Bril and Breniere (1992) posed the question whether children, at the onset of independent walking, were "learning to walk or learning dynamic postural control". They subsequently elaborated on this question by studying a sample of 11 children with less than 200 days I.W. experience. Dynamic equilibrium, or walking, is a coordinated motion involving the integration of posture and movement. Walking is a complex locomotor task for a new walker requiring the production of forward propulsion, maintenance of lateral stability, and body mass support by one leg during swing phase. The latter, one legged support, is a as the major balance issue faced by toddlers (Assaiante et al., 1993; Breneire, Bril \& Fontaine, 1989; Keogh \& Sugden, 1985; Lee \& Aronson, 1974).

Researchers focusing on different motor parameters have established multiple age dependent gait development models. Among them, a two stage model for children less than 4 years of age was proposed by Bril and Breniere (1990). This model was constructed based on studies of developmental variability and change in temporal and kinematic parameters, including gait cadence, step length, step width, velocity, double support duration and vertical acceleration of the center of gravity. According to this model, the first six months of independent walking are classified as the stage for integration of postural and locomotor requirements. The subsequent period up to the age of 4 to 6 years of age is described as the stage for regulating control of gait. Bril and Breniere (1990) reported that walking patterns changed dramatically over these two periods. After the age of 4 to 6 years, children display adult-like patterns during normal walking.

During the initial phase of the two stage gait development model, young walkers learn to maintain their equilibrium during walking as well as to create a propelling force for moving forward. In order to accomplish this, coordination between multiple components of gait is required. This phase of gait acquisition corresponds to a period of rapid growth, resulting in the maturation of the locomotor system reflected in a variety of locomotion pattern changes (Ogg, 1966; Burnett \& Johnson, 1971; Statham \& Murray, 1971; Sutherland et al., 1980; Beck et al., 1981; Phillips \& Clark, 1985; Forssberg, 1985; Clark, 1988; Bril \& Breniere, 1989, 90, 91, 92, \& 93). 
Various studies, each focusing on a particular set of gait variables, have shown support for the two stage gait development model proposed by Bril and Breniere (1990). These gait variables may be grouped into the following categories: temporal and distance, kinematics and kinetic, and electromyography (EMG).

\section{Temporal and distance variables}

Temporal and distance variables include step cadence, step length, step width, progression velocity, and double support duration.

Increases in single support duration and decreases in double support duration are among the most drastic changes recorded in the first six months of gait acquisition and they continue to change until the age of 3.5 to 4 years (Sutherland et al., 1988). These variables appear to be good indicators of the toddler's abilities for maintaining dynamic balance. The shorter duration of single support and the longer duration of double support act as the equilibrium recovery period suggesting an inability to maintain ipsilateral limb single stance while preparing contralateral limb swing.

The short step length and the greater step width recorded in toddlers compared to adults could also be interpreted as a compromise to meet the demands for balance control. Children display greater step width and out-toeing which facilitates maintenance of the projection of the centre of mass within a larger support base to achieve body equilibrium (Shirley, 1931; Ogg, 1966; Burnett \& Johnson, 1971). Step lengths rapidly increase following the initiation of independent walking up to 3 years of age.

Demands for balance control can also inferred from the low gait velocity. In correspondence to the increase of step length, the velocity increases rapidly in phase one of the gait development (Sutherland et al., 1988).

\section{Kinematic variables}

Kinematic variables depict the trajectories of body segments during movements without reflecting the underlying control through internal or external forces. Kinematic 
variables include orientation, velocity, joint displacements and accelerations, and movement of the center of mass.

Interestingly, during the first stage of gait development, a negative vertical movement of the centre of gravity at foot contact is reported (Bril \& Breniere, 1992). The negative vertical movement demonstrates a lack of the necessary force to propel the lower extremity for stepping forward. The observation can be explained using a twofold rationale. First, lower extremity muscle strength is not adequate to generate a propelling force; and second, there is no transition phase which prepares the lower limbs to move from the double stance period to the swing period.

In these two phases of a gait cycle, double and single support phases are performed as independent actions by children who are less than 4 years of age. This differs from the adults' gait patterns, where preparations for the next phase always occur in the current period throughout gait cycles.

The immature gait patterns displayed by children over developmental stages are also observed in the joint angle trajectories. In the sagittal plane, both knee and hip joints show less movement as indicated by the smaller angle of hip and knee flexion compared to adults. This is done to reduce the risks of instability (Sutherland et al., 1988). Children aged 1 to 1.5 years also show increased external hip and foot rotation during the stance phase in the transverse plane. When they reach 3 years of age, greater adduction of the hip in the frontal plane is displayed during the stance phase (Sutherland et al., 1988). Taken together, these differences suggest that a large support base is required by toddlers in order to control dynamic postural control during gait development.

\section{Kinetic \& muscle activity variables}

Kinematic variables describe spatio-temporal aspects of movement and do not provide insights to the muscle activity or the muscle, gravitational or movement-induced forces underlying locomotor patterns. Kinetic parameters describe the causes of specific movement and include muscle force, moment, mechanical power, and energy patterns. 
Using surface electromyography, activity from only a few muscle groups contributing to relevant force generation can be recorded, hence the database for young children is far from complete. Specifically, researchers have only managed to capture the activity of the gluteus maximus, gluteus medius, medial hamstrings, lateral hamstrings, vastus medialis, gastrocnemius, soleus, and tibialis anterior muscles (Forssberg \& Wallberg, 1980; Berger et al., 1982; Sutherland et al., 1988).

For children older than two, muscle forces generated to support walking can be inferred from analysis of movement and ground reaction forces. Oeffinger and colleagues (1997) reported that the second stage of gait development was characterized by increases in the magnitude of ankle dorsiflexion moment and decreases in hip power generation at initial hip extensor (H1) and pre-swing hip flexor (H3) phrases ( $\mathrm{H} 1$ and $\mathrm{H} 3$ phases defined by Winter, 1990). In addition, slight increases in ankle power absorption at Al and notable increases in generation at A2 occurred with increasing age. These findings suggested that toddlers tend to limit the muscle activity mostly to the hip in part to reduce intersegmental passive forces and moments induced by disequilibrium during the walking. Elimination of additional forces is exploited by young children to achieve dynamic postural control. Due to the physical constraints including immaturity of the motor system, children exploit different strategies by dually activating muscle groups in walking to compensate for ineffective feedback reactions triggered by sensorimotor inputs (Sutherland et al., 1988; Oeffinger et al., 1997).

The development of gait is the process mastering appropriate postural control for the purpose of keeping balance. The mastery of postural control initiates with reactive postural control. As the motor system evolves, additional reactive postural control paths are built and voluntary postural control is established for better adaptation within the locomotor context.

\section{Role of experience}

On reviewing immature gait patterns, inter and intra-subject variability frequently appears with less day to day repeatability in 5-16 year old children (Gorton et al., 1997). In middle childhood, dynamic postural control is still maturing and when comparing locomotor patterns during obstacle crossing displayed by middle age children compared with those of 
adults, it is clear that programmed adjustments made during obstacle crossing are not established in children. This has been attributed to not only the maturation process of motor system but also lack of repetition/practice of certain goal directed locomotor tasks (Gorton $e t$ al., 1997). In fact, the effect of practice by children in gait development has largely been neglected. A few studies focus on the question of practice versus development in nonlocomotor tasks and have demonstrated clear evidence of changes with intense task practice over short periods. Specifically, practicing automatic/feedback postural responses to platform perturbations showed increases in the number of and appropriateness of postural muscles recruited (Sveistrup \& Woollacott, 1997). The drawer pulling study discussed above (Witherington, 2002) also demonstrated that with experience, children gain greater sense of strength adaptation underlying the anticipatory postural adjustments.

It would be expected that repetition of locomotor tasks occuring in natural circumstances or as manipulated through training would help improve both gross and fine motor skills.

\section{Obstacle crossing/avoidance}

Postural control in static and dynamic modes has been acknowledged as a key factor in gait development. Most studies have centered on either its influence in acquisition of normal walking or its development. However, in the real world, young children are often challenged by obstructed surroundings and the need to generate appropriate adaptive actions. One of the subtle challenges faced by young children is to negotiate obstacles. By comparing the obstacle crossing performance of toddlers and children to the mature and consistent locomotor patterns displayed by adults, the discrepancy in strategies can be discovered, offering additional insights into gait/motor system development.

Numerous studies have explored locomotor adjustments made by adults while going over obstacles of different heights, widths, shapes, and sizes. (Patla et al., 1989, 1991; Chen et al., 1991; Sparrow et al., 1996 ; Austin et al., 1997). These findings help us to understand the effects of the object location on the walking path, cue time, the presence of distracters during walking, the influence of physical impairment and/or deterioration on obstacle crossing strategies in terms of dynamic postural control. Performing similar studies with 
young children will enable us to gain insights in terms of the integration of motor subsystems. Moreover, it is important to examine the course of development of dynamic postural control throughout infancy and early childhood.

\section{Randomly present obstacle}

Patla and colleagues (1991) elaborated the strategies used for clearing obstacles of different heights when presented at different cue times and at different location within the step cycle. Ample adjustments were observed in the high obstacle condition while no changes were found either at the limb or trunk level in the low obstacle condition. When stepping over high obstacles, the trajectory of the stance limb did not vary but upward displacement of the body center of mass was provided by increasing the activity of the extensor muscles and decreasing the activity of flexor muscles. Swing limb trajectory was altered with either increased rectus femoris muscle activity after toe-off acting to flex the hip joint, increasing hamstring activity producing greater knee flexion or increasing tibialis anterior muscle activity resulting in increased ankle dorsiflexion providing sufficient toe clearance. In addition to modulation of the vertical trajectory of the swing foot, forward progression velocity decreased as the leading limb crossed over obstacles. Cue time, defined as the amount of time available for the subject to see the object before having to cross over it, has a tremendous influence on progression velocity and muscle activity during obstacle crossing. In early cue conditions, the horizontal braking pulse changed with the increase of obstacle height whereas the same amount of braking pulse were found regardless of obstacle height under late cue conditions. Greater muscle responses were also observed when cue time was less than one step cycle, especially for high obstacles. This reconfirms the observed effects of cue time on the horizontal braking pulse. In the swing limb, biceps femoris, tibialis anterior, and rectus femoris act together to increase flexion at the hip and knee joints and to increase dorsiflexion at the ankle joint. At the same time, soleus action required by stance limb was increased for the duration of the stance phase and continuously supported the increasing vertical braking impulse. When the cue time provided was two steps before the obstacle, a success rate of $100 \%$ was observed regardless of other experimental manipulation suggesting that the location of the obstacle had no effect on the participants. 
Hence, the time available for adjusting gait when encountering obstacles determines whether an individual will be able to safely go over the obstacles. In other words, sufficient cue time had allowed anticipatory locomotor adjustments to be made in order to better adapt postural requirements for going over the obstacles safely.

\section{Fixed obstacles}

Most studies have focused on investigating how postural related adaptations were modulated to negotiate visible, fixed obstacles. Such preparation, anticipatory locomotor adjustment, occurs in accordance with changes in environment (McFadyen \& Winter, 1991).

Based on the previous literature, the essential anticipatory adjustments in obstacle crossing adopted by young, older adults and children respectively are summarized in terms of seven parameters.

Healthy young adults

As discussed earlier, postural control is critical for completing various locomotor tasks. In obstacle crossing, a subtle complex locomotor task, the center of body mass shifts more than during normal walking. To maintain postural control, greater displacements of limbs are displayed in order to keep the center of mass within the support base. Such changes suggest that the motor system makes compensatory actions for safely navigating the obstacle. Researchers have been interested in documenting the specific locomotor pattern changes made by healthy young adults while going over an obstacle.

\section{Step length, width, and velocity}

Using a model of the neuromuscular-skeletal system, Taga (1998) reported that step length is manipulated when approaching. The decrease in step length is due, in part, to an increase in step width that occurs several steps prior to the obstacle (Vallis \& McFadyen, 2003). This planned variance provides maximum assurance that the center of mass (COM) is kept within the support base to limit the risk of falling during obstacle crossing. For the same reason, horizontal speed when crossing over the obstacle is reduced compared to unobstructed walking. This provides the sufficient time for limb adjustments in order to go 
over the obstacle safely (Patla et al., 1991; Chen et al., 1991; Patla \& Rietdyk, 1993; Patla et al., 1995; Sparrow et al., 1996). In addition, the greater toe vertical velocity after the obstacle suggests that rapidly moving the center of mass back to the support base minimizes the risk of falling (Patla et al., 1991; Chou et al., 2001).

\section{Knee flexion and hip elevation}

A knee flexion of the leading limb strategy is used during obstacle crossing and other joint activities, such as decreases in hip elevation and reductions in knee extension are deployed in favor of this strategy, (McFadyen \& Winter, 1991; Patla et al., 1996). MacFadyen \& Winter (1991) suggested a knee flexion strategy, minimal muscle activity in order to provide sufficient foot elevation over the obstacle, was exploited in order to achieve energy efficiency. The vertical foot displacement over the obstacle is also attributed to hip flexion and ankle dorsiflexion which are caused by knee flexion as the effect of passive intersegmental dynamics (Eng et al., 1994). In addition, it had been demonstrated that only knee flexion is monitored by CNS (Eng et al., 1994) and thus suggests that the CNS is responsible for balancing demands related to safety and energy efficiency. Therefore, it is understandable that knee flexor and extensor activities of leading limb changed online with the knee flexion strategy as obstacle locations varied (MacFadyen et al., 1993). To favor leading limb knee flexion, both hip and trunk elevation along with trailing limb extension occur. Modifications in the trailing limb were achieved by reducing the knee flexor activity and increasing knee extensor and ankle plantar flexor activity (Chou \& Dragnich, 1996; Chen \& Lu, 2006). Trailing limb extension was also characterized by greater vertical and anterior-posterior ground reaction forces at push-off (Begg, 1998).

\section{Toe clearance}

Toe clearance (TC) over the obstacle also reflects the importance of safety for obstacle crossing. The TC value of the leading limb is approximately $10 \mathrm{~cm}$ (Patla \& Rietdyk, 1993) versus an average TC of $0.87 \mathrm{~cm}$ during normal walking (Winter, 1989). These findings indicated that safety takes priority over energy efficiency when obstacle crossing. Interestingly, TC of the leading limb increases as a function of obstacle height to ensure a sufficient margin over the obstacle but this increase ceased when the obstacle 
height reached approximately $8 \mathrm{~cm}$ (Patla et al., 1991; Sparrow et al., 1996; Austin et al., 1999). In contrast to TC changes in the leading limb, the TC of the trailing limb is not influenced by increases in obstacle height (Chou \& Draganich, 1998). This is probably because adjustments of leading limb are prepared in advance before going over the obstacle with the aid of vision.

Besides the height of the obstacle, vision also provides us with other information regarding obstacle features, such as proximity, properties, shapes, numbers and width. Among these features, only the properties of obstacle (fragility and rigidity) have been shown to influence TC of the leading foot (Patla et al., 1991; Spaulding \& Patla, 1991; Patla \& Rietdyk, 1993; Patla et al., 1995; Krell \& Patla, 2002). Specifically, fragile obstacles induced greater TC in the leading limb compared to rigid obstacles (Patla \& Rietdyk, 1993) again suggesting that safety is essential in obstacle crossing and that it is ensured by vision (Mohagheghi, 2004).

Finally, locomotor adjustments in obstacle crossing are assisted by anticipation. Hence, going over visible, fixed obstacles can be considered as a voluntary act. However, when surroundings change and consequently became postural threats that influence the TC of the leading and trailing foot (McKenzie \& Brown, 2004), reactive locomotor adjustments emerge to ascertain safety in obstacle crossing.

\section{Toe off and heel contact distance}

Safety can only be ensured when adequate time is allowed for the completion of locomotor adjustments prior to and over the obstacle. Sparrow and colleagues (1996) showed that the leading foot crosses an obstacle earlier as a function of obstacle height, yet the crossing distance remains unchanged at about $80 \%$ of normalized stride length across obstacle heights. More adjustment time was provided for higher obstacles so that risks of tripping are reduced. The constant lead foot positions suggested that the energy efficiency of motor system is also managed in association with safe crossing.

Comparatively, the position of the trailing foot is not consistently influenced by changes in obstacle heights. In fact, the trailing foot position is adjusted in association with 
leading foot placement only if lead foot placement prior to the obstacle is changed due to absence of on-line visual information (Mohagheghi, 2004).

\section{Elderly}

As reported in previous studies, a significant percentage of the elderly population, approximately one-third, falls at least once a year (Tinetti \& Speechley, 1989). A large proportion of these events are due to trips caused by obstacles.

Aging related changes in motor systems result in alterations in locomotor patterns of older adults during obstacle crossing. Safe and consistent obstacle negotiation requires compensatory locomotor adaptation regulated by CNS (Chen et al., 1991, 1997; Patla et al. 1996; Draganich et al., 2001; Chou et al., 2003; Hahn \& Chou, 2003; McKenzie \& Brown, 2004; Lu et al., 2006).

\section{Success rate}

Success rate is a direct index of obstacle crossing performance that could be used to indicate performance deterioration in an elderly population. In fact, it was reported that older adults stepped on the obstacle more often than young adults (Chen et al., 1991; Patla et al., 1996). A lower percentage of success suggests that age-related changes endanger older adults who may lose balance while circumventing obstacles. Therefore, to avoid tripping and falling over obstacles, conservative strategies are used by older adults.

Step length, width, and velocity

As documented, features of aging that contribute to the use of conservative strategies during obstacle crossing by older adults include the deterioration of muscle strength and vision (Chou et al., 2003; Leibowitz et al., 1979; Brandt et al., 1986). In order to reduce the risks of tripping and falling, older adults decrease crossing speed, decrease crossing step length, and increase the step width over the obstacle (Chen et al., 1991). These conservative strategies reflect the older adults' preference in maintaining stability over energy efficiency, specifically by: 1) slowing speed to provide sufficient reaction time; 2) decreasing step length to ensure a safe landing by moving the COM rapidly back to the support base; and 3) 
increasing step width to keep the COM within the wider support base. In addition, decreasing the anteroposterior distances between the COM and the center of pressure not only prevents falling but also facilitates recovery from tripping during obstacle crossing (Chou et al., 2003).

\section{Toe clearance}

Patla and his colleagues (1996) examined sixteen young and older subjects and compared the vertical displacements of the toe as obstacle height increased. Older adults demonstrated higher toe clearance in contrast to young adults and TC increased as function of obstacle height. These findings were supported by $\mathrm{Lu}$ (2006) but contrast those of Chen (1991). This difference is probably due to the harness system used by Chen which provided extra safety assurance for older adults in the experiments. When encountering an obstacle terrain without protection, older adults intend to exploit full advantage of motor system to achieve safe margin over the obstacle.

\section{Knee flexion and hip elevation}

To ensure an adequate margin over the obstacle, older adults use greater hip elevation in addition to knee flexion. Moreover, as obstacle height increased, the proportion of hip elevation contributing to TC increases (Patla et al., 1996). This phenomenon was confirmed by the changes of translational energy shown at hip joint (Patla et al., 1996). Normally, hip elevation is considered as a destabilising force which disturbs upper body balance, therefore this strategy of obstacle is not exploited by young adults, who rather increase knee flexion as a function of the obstacle height. The advantage of smaller range of motion (ROM) at leading knee joint is to simplify the landing of leading limb in order to ensure the stability and provide appropriate distance for trailing foot to take off. Older adults take this advantage as assurance of safety, but trade-off energy conservation. This strategy suggests that safety is the dominant criteria for postural control in obstacle crossing and has been through a study comparing locomotor patterns of young adults and those of a theoretical model created based on minimal mechanical energy principles (Chou et al., 1997). 


\section{Toe off/heel contact distance}

The relative priority of safety is also seen in the pre- and post-obstacle foot placement position used by the older adult. Specifically, older adults position their feet further away from the obstacle at toe-off prior to the obstacle and land their feet closer to the obstacle in contrast to young adults (Chen et al., 1991; Patla et al., 1996). The reasons for decrease of toe/heel distance of leading limb prior to/after the obstacle respectively are twofold. Longer toe distances to the obstacle will enable the older adult adequate time to modify limb trajectories. At the same time, not to place the trailing foot as close to the obstacle as the leading foot reduces risks of tripping.

\section{Children}

Similar to older adults, young children's ability in completing obstacle crossing is limited by poor integration of motor components. Motor components of toddlers have not yet integrated to form an intact system (Patla et al., 1996) and the under developed motor system is a restriction to their locomotion. With increase of age, older children are more capable to exert prospective postural control to accomplish specific locomotor tasks. In terms of locomotor adjustments, performance of older children is closer to that of young adults (Patla, et al., 1996; Krell \& Patla, 1997; MacFadyen, 2001; Vallis \& MacFadyen, 2005; Berard \& Vallis, 2006).

\section{Toddlers}

To date, there has been little literature discussing locomotor changes made by toddlers while stepping over obstacles with one preliminary study (Patla et al., 1996) reporting minimal kinematic data of obstacle avoidance from four toddlers aged between 14 and 30 months.

\section{Success rate}

Fifty percent of the trials recorded were categorized as failures due to toddlers stepping onto the obstacle, falling, tripping over the obstacle or refusing to cross the obstacle. 
This suggests that integration of postural control systems has not yet been established in association with this specific locomotor task.

\section{Toe clearance, hip elevation, and toe/heel distance}

The toe clearance and relative contribution of hip elevation to the toe margin in the toddlers showed similar patterns to those of older adults while toddlers demonstrate greater variability of toe-off distance prior to the obstacle (Patla et al., 1996). These authors suggested that anticipatory adjustments were not incorporated into postural control by toddlers for going over the obstacle and suggested that only once motor components are fully integrated can consistent maneuvers be produced to negotiate obstacles.

\section{Older children}

Motor component integration is a progressive process lasting through middle childhood (6-15 years age). In particular, when children of this age group attempted in circumvent multiple obstacles, inconsistent locomotor anticipatory adjustments were exhibited and other compensatory actions were employed to achieve safe margins over the obstacles (Krell \& Patla, 1997; Vallis \& McFadyen, 2005, Berard \& Vallis, 2006).

Without the appropriate take off foot position prior to the obstacle, higher toe clearances and greater crossing step lengths were used to ensure safety during obstacle crossing (Krell \& Patla, 1997; Berard \& Vallis, 2006). In addition, suitable anticipatory adjustments for preparing the action of going over an obstacle are made according to the reference system for body orientation. When the child can not locate an accurate self motion image relative to the chosen reference to trigger obstacle crossing, the fluent action of negotiating the obstacle is broken down into two simpler actions, i.e. steering and moving (Vallis \& McFadyen, 2005). Steering indicated by reorientation of head and trunk occurs prior to the change of direction of the M-L COM and ensures ongoing direction. Continuously moving provides sufficient margin over the obstacle (Vallis \& McFadyen, 2005).

These locomotor patterns changed for children of different ages indicate that the motor integration continues across middle childhood. 


\section{Role of experience}

Development of postural control involves motor skill acquisition. It is achieved not only through maturation of motor mechanisms, but also with motor learning/practice. Moreover, different postural movements are used by combining strategies of different magnitudes and temporal relations and that may have been influenced through past experience (Horak \& Nashner 1986; Berthoz \& Viaud-Delmon, 1999). In the adult, the consistent patterns of locomotion during obstacle crossing tasks are a reaction to specific environmental contexts and achieved through practice.

Children primarily gain motor experience in natural settings through repetition of various motor skills. When the physical constraints are diminished and muscle memory is established, context dependant automatic and proactive locomotor reactions would then emerge to help coping with different environmental situations.

\section{Summary}

Regardless of age or physical ability, walking in a cluttered environment is inevitable. It could be argued that new walkers rarely walk outside and are protected to stay away from such environment. However, even at home, they would still be surrounded by toys and other obstacles. Compared to unobstructed gait, obstacle crossing is more complex due to the greater deviation of the COM from the support base. To perform a safe and efficient obstacle negotiation not only requires the interaction and coordination of all motor system components but also some further fine-tuning. In reducing the comparatively greater risk of falling of obstacle crossing, young children place safety in a more dominant position.

The rationales for obstacle crossing being a challenge to early independent walkers are twofold. Firstly, during early stages of gait development, new walkers struggle in coordinating multiple postural control systems even during unobstructed walking. Laying an obstacle on their walking path will force them to adjust their limb displacements while maintaining control for safely going over the obstacle. Secondly, with no or little former obstacle crossing experience, they could not have gained any sense on how to traverse the obstacle without tripping or even falling. The present study explored locomotor adjustments 
of the lower limbs made by toddlers as they crossed over obstacles in order to provide a better understanding of gait development in terms of dynamic postural control.

We hypothesized that 1) compared with unobstructed trials, toddlers would decrease the length of the step crossing an obstacle; 2) knee flexion of the leading limb will be significantly greater when stepping over an obstacle versus that exhibited during unobstructed walking, 3) Toe clearance over an obstacle will be greater than that of adults as reported previously in the literature; and 4) toe clearance over an obstacle will decrease from 1 month of IW to 8 months of IW. 


\section{CHAPTER III}

\section{Methodology}

\section{Participants}

This is a cross-sectional study of eight toddlers (six males and two females; mean height $80.6 \mathrm{~cm}$ ) with between 1 to 8 months of independent walking experience (from 15 to 19 months of age). Subject characteristics are shown in Table 1. Parents/guardians of the children signed an information and consent form consistent with the Tri-Council Policy Statement on the Ethical Conduct for Research involving Humans that was approved by the Research Ethics Board of the University of Ottawa. Toddlers were included if they had experienced typical motor development by parental report on birth complications and the appearance of motor milestones.

Table 1. Subject Characteristics

\begin{tabular}{cccccccc}
\hline Subject \# & $\begin{array}{c}\text { Months } \\
\text { walking }\end{array}$ & $\begin{array}{c}\text { Age } \\
\text { (months) }\end{array}$ & Gender & $\begin{array}{c}\text { Mass } \\
\text { (kg) }\end{array}$ & $\begin{array}{c}\text { Height } \\
\text { (cm) }\end{array}$ & $\begin{array}{c}\text { Leg } \\
\text { length } \\
\text { (cm) }\end{array}$ & $\begin{array}{c}\text { leg length } \\
\text { as \% of } \\
\text { height }\end{array}$ \\
\hline 1 & 1 & 15 & F & 9.1 & 73.5 & 33 & 45 \\
\hline 2 & 2.5 & 15 & F & 10.0 & 74 & 37 & 50 \\
\hline 3 & 3 & 16 & M & 11.1 & 83 & 41 & 49 \\
\hline 4 & 3.5 & 15 & M & 11 & 81 & 40 & 49 \\
\hline 5 & 4 & 15.5 & M & 11.8 & 78.5 & 36 & 46 \\
\hline 6 & 5 & 18 & M & 12.5 & 89.5 & 46 & 51 \\
\hline 7 & 7.5 & 17.5 & M & 11.8 & 85 & 41 & 48 \\
\hline 8 & 8 & 19 & M & 11.3 & 80 & 36 & 45 \\
\hline
\end{tabular}




\section{Experimental paradigm}

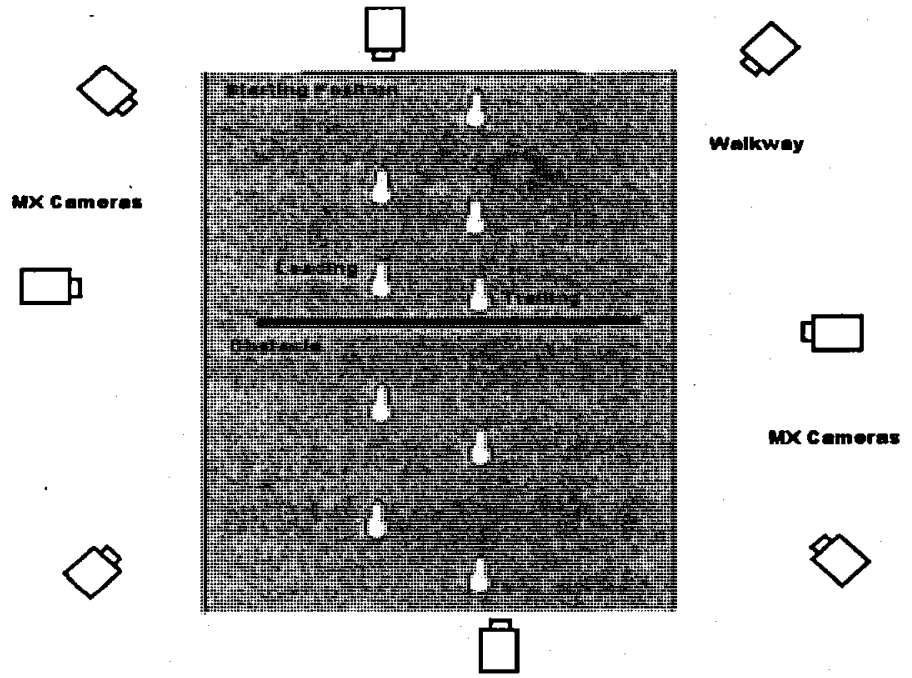

Figure 1. Experimental Setting and Devices

Data acquisition was completed in Sensorimotor Neurosciences Laboratory, University of Ottawa. Parents placed their toddler on the floor at one end of a $4 \mathrm{~m} \mathrm{x} 1 \mathrm{~m}$ walkway and then stood at the other end of the walkway to encourage the toddler to walk towards them (Figure 1 above). This process was repeated several times to obtain data for at least 5 walking trials with an obstacle placed across the walkway and 5 trials without the obstacle. The obstacle consisted of a brightly colored $4.5 \mathrm{~cm}$ diameter foam tube taped perpendicular to the walkway and was roughly $10 \%$ of average subjects' leg length (McFadyen, Magnan \& Boucher, 1993). The session ended with either a full dataset or when either the toddler or the parent refused to continue.

\section{Data acquisition}

Lower extremity segment lengths were recorded for the thigh (between the greater trochanter of the femur and lateral femoral condyle), shank (between the lateral femoral condyle and lateral malleolus of the fibula) and foot (between the lateral malleolus and the fifth metatarsophalangeal joint). Thigh and shank girths at the widest diameter and foot width at the widest spot were recorded. Finally, the toddler's body height in supine and mass were recorded. 
Kinematic data were collected using a three-dimensional optical tracking system (VICON motion analysis system, Oxford Metric Ltd, Oxford, UK). Lower extremity movement was recorded using eight MX cameras sampling at $200 \mathrm{~Hz}$. Between $\mathrm{X}$ and $\mathrm{Y}$ steps were recorded for each unobstructed trial. Between $\mathrm{X}$ and $\mathrm{Y}$ steps were recorded prior to and post obstacle crossing in the remaining trials. For measurements of the lower extremities, reflective markers were placed on the head and over the shoulder (acromion), hip (anterior superior iliac spine), knee (lateral condyle), ankle (lateral malleolus), heel, and toe ( $5^{\text {th }}$ metatarsophalangal joint) each side of the body. Additional markers were placed on both ends of the obstacle.

\section{Data reduction}

At least five trials each of unobstructed and obstructed walking were digitized for quantification of gait characteristics. Lower extremity trajectories of ten steps from each unobstructed walking trial and six steps from each obstacle crossing trial were generated for each subject. Data were low-pass filtered using a Butterworth, zero-lag, $6 \mathrm{~Hz}$ low pass filter. Step length, step height, obstacle toe clearance, hip, knee and ankle angles, pre-obstacle toe distance, post-obstacle heel distance were calculated (Figure 2a, b, c) using Visual3D Motion Analysis System (C-motion Inc, Rockville, Maryland. US). For obstacle crossing trials, two joint angle values were extracted from the joint trajectories: 1) joint angle when the toe was over the obstacle; and 2) maximum joint angle for the obstacle crossing trial regardless of where this occurred during the trial.

Descriptive analysis of all trials recorded focused on the number of contacts made with the obstacle by the leading and trailing foot as well as the number of falls resulting from obstacle contact. 

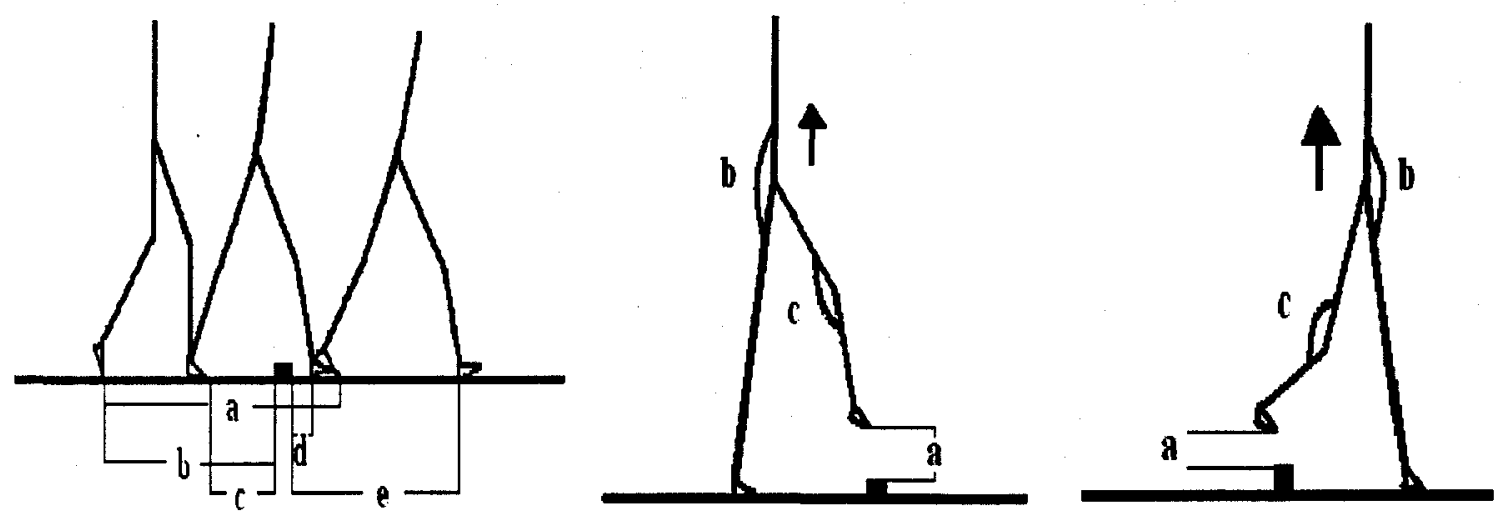

a. Step length

b. Lead toe off distance

c. Trail toe off distance

d. Lead heel contact distance

a. Lead toe clearance

a. Trail toe clearance

b. Hip extension

b. Hip extension

c. Knee flexion

c. Knee flexion

Figure 2. Dependent Variables

\section{Data analysis}

A qualitative analysis of the data was first performed, focusing on general patterns of toe, knee and hip joint kinematic trajectories during obstructed and unobstructed gait that were observed (Sveistrup \& Woollacott, 1996). The variation as well as consistency within and between the profiles of the individual infant's movements as they stepped over the obstacle will be discussed.

Subsequently, a quantitative analysis was employed to explore locomotor behaviour changes in toddlers between conditions as well as over months of walking. For each toddler, data were averaged within each condition and mean values were used to represent the individual toddlers' behavior. The changes in locomotor characteristics were analyzed using the following statistical methods: bivariate regression and paired-sample $t$-tests. Pair-wise $t$ tests were used to determine condition-induced differences in the magnitude of toe clearance, step length, and maximum knee and hip joint flexion. It was also used to compare differences between leading and trailing limb in over obstacle trials. To track the trend of toe clearance changed from 1 month to 8 months of IW, bivariate regression was performed. 


\section{CHAPTER IV}

\section{Results}

\section{Qualitative analysis}

Spatial trajectories of toe, knee, and hip best demonstrate the progressive motor behavior changes of toddlers during obstacle crossing. Trajectories of the ankle, knee and hip of the leading and trailing limbs are plotted for obstacle crossing steps from toe off to heel contact for each toddler separately (Figure 3a-h). Each figure illustrates, from top to bottom, the trajectories of markers on the hip, knee and ankle joints for five steps. For two children, data sets were incomplete: a) two hip marker trajectories are plotted for toddler 2; and b) data from four trials are plotted for toddler 4 . The fixed obstacle is indicated as a black rectangle.

Overall, these figures suggest that toddlers with more walking experience have greater control of their lower extremities as evidenced by the more consistent take off and landing positions of both the leading and trailing limb albeit with some exceptions as discussed below. Furthermore, it was observed that the further away the toe off position to the obstacle, the lower the leading toe clearance. In addition, in toddlers with less than 4 months of IW experience, the take off position of the trailing foot is closely followed by the leading foot prior to the crossing step. In contrast, this didn't appear in toddlers with longer walking experience. When the leading limbs of older toddlers are going over the obstacle, a well positioned trailing toe of the supporting limb provides the proper distance required for guiding the leading limb over the obstacle. The trajectories of hip change with IW experience becoming increasingly linear. Among the eight toddlers, the four with less walking experience displayed hip elevation that assisted with toe clearance. In the toddlers with more IW experience, four months and more, the contribution of the hip to toe clearance decreased.

In general, three segmental trajectories are used to represent lower extremity locomotion changes in the obstacle negotiation task. 
Two stage development (Bril \& Breniere, 1990)

Integration stage (Bril \& Breniere, 1990)

The six toddlers with the least independent walking experience (1 to 5 months) appear to be in the integration stage. These toddlers fell or demonstrated greater risks of falling compared to toddlers with greater IW experience. In the toddlers, falls or risk of falls resulted from the leading or trailing foot kicking the obstacle, sliding beneath the obstacle or landing on the obstacle. These behaviors occurred when no anticipatory adjustments were made to the locomotor patterns until the very last step prior to obstacle crossing even though the obstacle was fixed and visible.

In contrast to the later independent walkers, hip elevation contributed more to the toe clearance height over the obstacle in the early walkers.

Tuning stage (Bril \& Breniere, 1990)

Other two toddlers with 7.5 and 8 months IW experience is categorized in the tuning stage. Their toe off positions and toe clearance in leading and trailing limb are relatively fixed to the obstacle. Hip does not show influence on the toe clearance. Knee flexion became the single contributor to the toe clearance. There was only one trial (in toddler 7) in which the position of toe off does not favor the crossing.

\section{Individual observations}

Toddler 1 (1 month IW)

In toddler1 (Fig 3a), the progression path over the obstacle varies greatly between trials. The inter-trial variability is reflected in leading and trailing toe off positions prior to the obstacle as well as in the landing positions of the leading and trailing heel. It was found in four trials out of five that leading or trailing foot was positioned on or touching the obstacle. For example, in trial 2, the leading foot first stepped on the obstacle, continued its forward progression by sliding over the obstacle and ended landing close to the obstacle. Toe clearance over the obstacle also showed great variability. In three out of five trials, the leading toe passed just over the obstacle while in trial 1 , the margin of toe clearance was 
exceptionally great. For leading and trailing limb, the trajectory paths of knee and toe have same shape. The hip vertical and horizontal movement also appears to be closely associated with toe and knee movements.

Toddlers 2, 3, 4 (2.5, 3, 3.5 month IW)

The segmental trajectories for toddlers with 2.5, 3, and 3.5 months of IW experience demonstrate several similarities (Fig 3b, c, d). Crossing trajectories trial vs. trial showed less variance compared to toddler 1 . First, there is less inter-trial variability observed in the leading and trailing toe off and heel contact positions as well as in the toe clearance height. These toddlers tended to approach the trailing foot closer to the obstacle with the take off position of leading foot close to the trailing foot. Interestingly the leading foot also landed close to the obstacle while the landing position of the trailing foot kept a more constant distance from the obstacle. Knee flexion appears to be a critical factor to toe clearance height whereas hip elevation seems to have less of an influence.

Compared to toddler 1 , these toddlers placed both the leading and trailing toe closer to the obstacle for most trials although errors positioning of toe at take off and the heel at landing still occurred in some trials. The leading toe of Toddler 2 in trial 4, for example, stepped on the obstacle, subsequently lifted off and then slide over the obstacle. This was followed with the leading heel also landing on the obstacle. In toddler 3 , the leading heel landed on the obstacle in trial 3 while, with 0.5 month more walking experience, toddler 4 displayed less error in the positioning of leading toe. In this toddler (4), the leading toe touched the edge of the obstacle in trial 5 only.

\section{Toddlers 5, 6 (4, 5 month IW)}

In toddlers 5 and 6, joint trajectories as well as the positions of the leading and trailing toe prior to the obstacle are more consistent (Fig 3e, f). In a single trial, toddler 5 demonstrated a pattern with the leading toe take-off position far ahead of the obstacle. However, despite the inconsistency in the leading toe position, the pre- and post-obstacle positions of the trailing toe were consistent between trials suggesting compensation occurred. Compared to toddlers 2,3 , and 4 , the landing position of the leading foot was farther from 
the obstacle for toddlers 5 and 6 while the landing position of trailing foot remained almost the same. A more stable postural control can also be inferred from the relatively stable height of toe clearance across trials. Additionally, hip movements appear to contribute less to the toe clearance height.

Toddler $7,8(7.5,8$ month IW)

The trajectories of the toe, knee, and hip from toddlers 7 and 8 begin to take the shape of those displayed by adults (Fig $3 \mathrm{~g}, \mathrm{~h}$ ). In the graph, the height of toe and knee of the leading limb showed gradually increase as crossing over the obstacle whereas that of hip remains flat. In the trailing limb, the height of toe appears to be decreased at swing phase whereas that of the knee and hip is unchanged. Compared to the later walkers, the touchdown position of the trailing toe in toddlers 7 and 8 moves further away from the obstacle.

In contrast to toddlers 4 to 6 , toe clearance height in the leading and trailing limb varied across trials in toddler 7 and then became, once again, more consistent in toddler 8 . In both toddler 7 and 8 , the hip trajectory patterns appear straight suggesting that the contribution of the hip to toe clearance decreases in toddlers with more than six months of independent walking experience.

\section{Quantitative analysis}

Data were collected that covered the first eight months of IW. Mean and standard deviations of eighteen variables for each toddler were computed.

Locomotor characteristics during obstacle negotiation were recorded and compared to unobstructed walking. The changes in locomotor characteristics were also explored in terms of independent walking experience.

\section{Success rate}

To assess the overall performance of obstacle crossing in toddlers, the rate of success provides a unique perspective in observing toddlers' capability of task achievement. Table 2 
shows that, in general, number of trials where the obstacle was successfully cleared by the leading and trailing limbs increased with the months of walking. The sole exception was with the 2.5 month IW toddler who had less successful obstacle crossings than the 1 month IW toddler. Correspondingly, the numbers of trials where the leading foot contacted the obstacle decreased as months of IW increased. However, although the number of times the trailing foot made contact with the obstacle decreased as walking experience increased, the relationship appeared less immediate. In addition, toddlers with less IW experience attempted to crawl instead of walk over the obstacle in some trials.

\section{Step length (SL)}

Figure 4 illustrates step lengths of the leading and trailing limbs during obstacle crossing and unobstructed walking trials. In general, the step lengths of the leading and trailing limbs over the obstacle were greater than in unobstructed walking while the step length of the trailing limb was greater than that of the leading limb. In addition, step lengths both in obstacle crossing trials and unobstructed walking trials increased over months of walking. Pair-wise comparisons revealed significant differences between leading limb step lengths in obstacle crossing versus unobstructed walking trials $(\mathrm{p}=0.000)$; trailing limb step lengths in obstacle crossing versus unobstructed walking trials $(\mathrm{p}=0.000)$; and leading versus trailing limb step lengths in obstacle crossing trials $(\mathrm{p}=0.001)$.

\section{Toe clearance (TC)}

The height of toe is significantly greater when clearing the obstacle compared to during unobstructed walking for both the leading and trailing limb. Moreover, toe clearance in both the leading and trailing limb increased as the months of walking experience increased. Pair-wise comparisons revealed significant differences in obstacle crossing and unobstructed conditions (leading limb: $p=0.001$; trailing limb: $p=0.000$ ) while there was no difference in toe clearance height of the leading and trailing limbs $(\mathrm{p}=0.017)$. Figure 5, illustrates leading (top) and trailing limb (bottom) toe clearance during obstacle crossing and unobstructed walking trials as a function of months of walking experience.

To better understand the relation between toe clearance over the obstacle and months of walking, regression analysis was used. To minimize type II error, non parametric 
regression analysis was used. The results showed that TC of leading and trailing foot was highly correlated to the months of walking ( $p=0.018, r=0.738 ; p=0.000, r=0.952)$. Furthermore, the trailing TC showed months of walking effect, $F(1,6)=39.716, p=0.001$, but not leading $\mathrm{TC}, \mathrm{F}(1,6)=4.326, \mathrm{p}=0.083$.

\section{Toe off and heel contact distance (TD \& HD)}

Leading and trailing limb toe and heel distances prior to and after the obstacle are illustrated in figure 6. For each toddler, data from five trials are plotted against months of IW experience. The toe off and heel contact distances of the leading limb increased slightly with months of IW although the change was not consistent. Although the increase in distance to the obstacle was also observed in the trailing limb, most apparently in the heel contact distance, the change was also inconsistent.

As seen in figure 6, the distance of the toe ahead of the obstacle is highly variable. Although still variable, there appears to be a clustering of obstacle to heel distance that becomes increasingly consistent with months of IW experience.

Using table 3, values of TD and HD for each of the five trials belonging to each toddler were displayed.

\section{Hip and knee joint angle}

Leading and trailing limb hip and knee joint angles during obstacle crossing and unobstructed walking were compared. The results of pairwise comparisons are shown in Table 4. Significant differences were identified for all comparisons made between walking conditions while between limb comparisons show minimal inter-limb differences. As indicated in the table 4, the amount of knee flexion and hip extension of both leading and trailing limb is significantly greater in obstacle crossing trials than unobstructed trials. Comparatively, the inter-limb angles showed less variance in magnitude when compared to condition induced angle differences. 


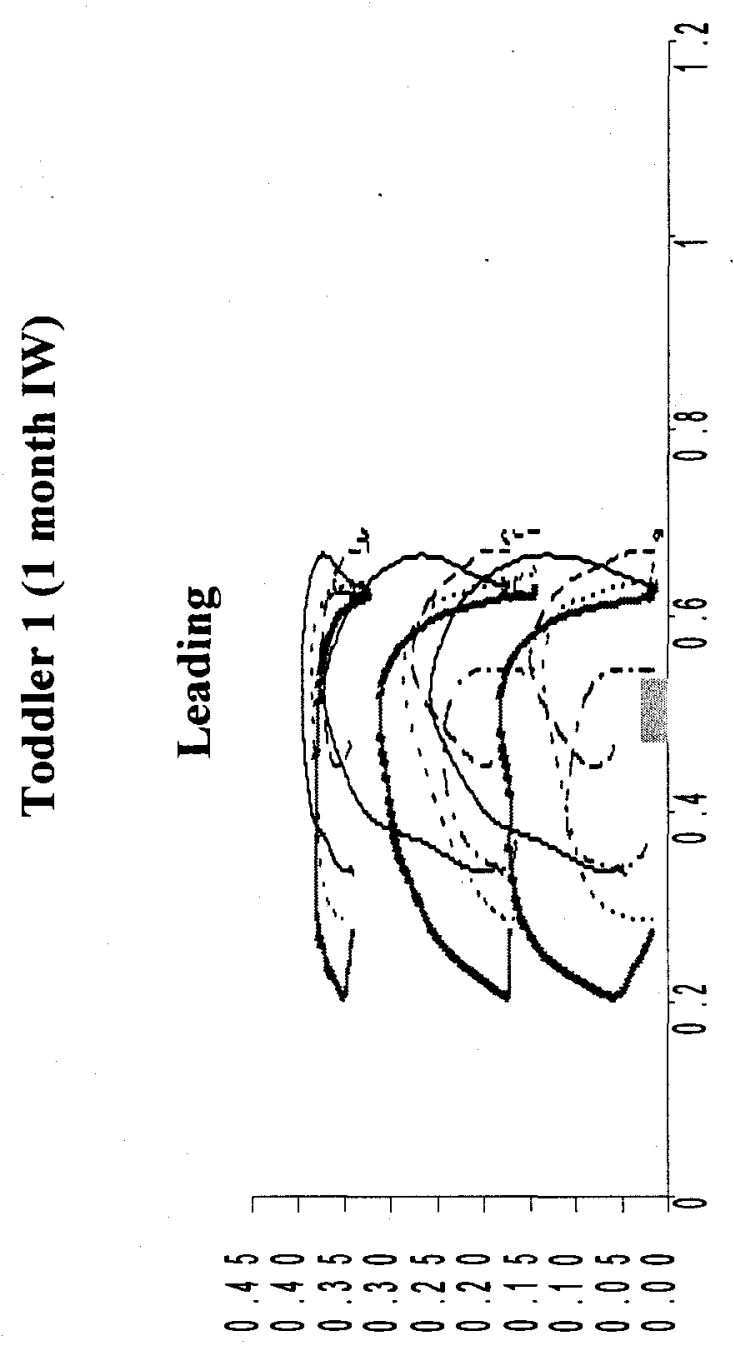

ธ

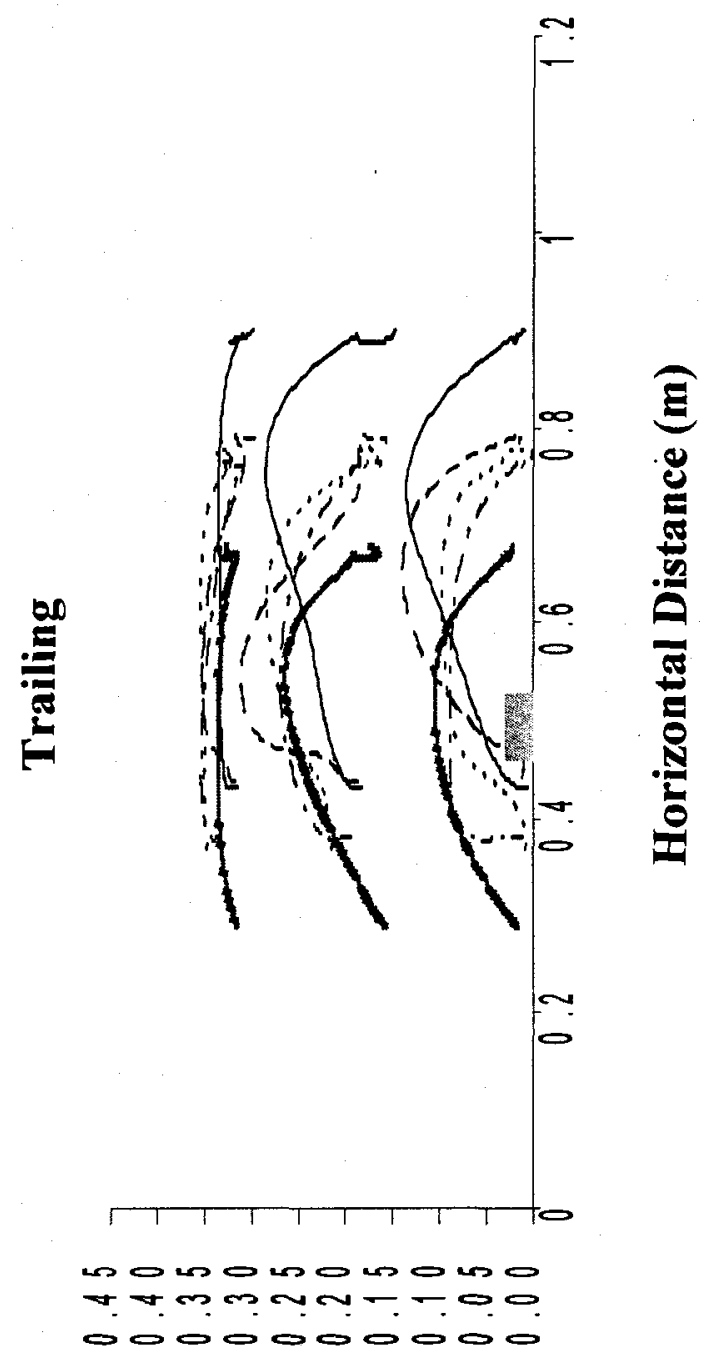

(ui) 7 มิธิเอH 


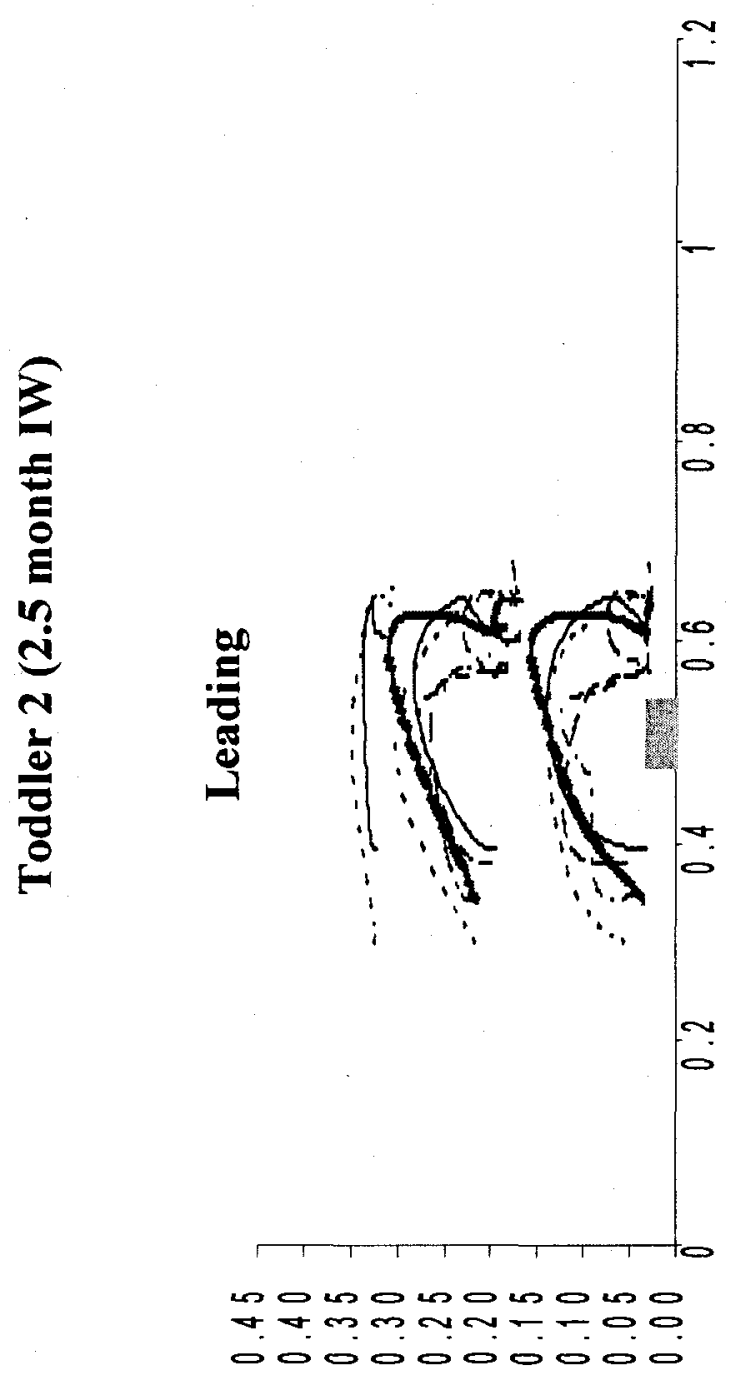

0

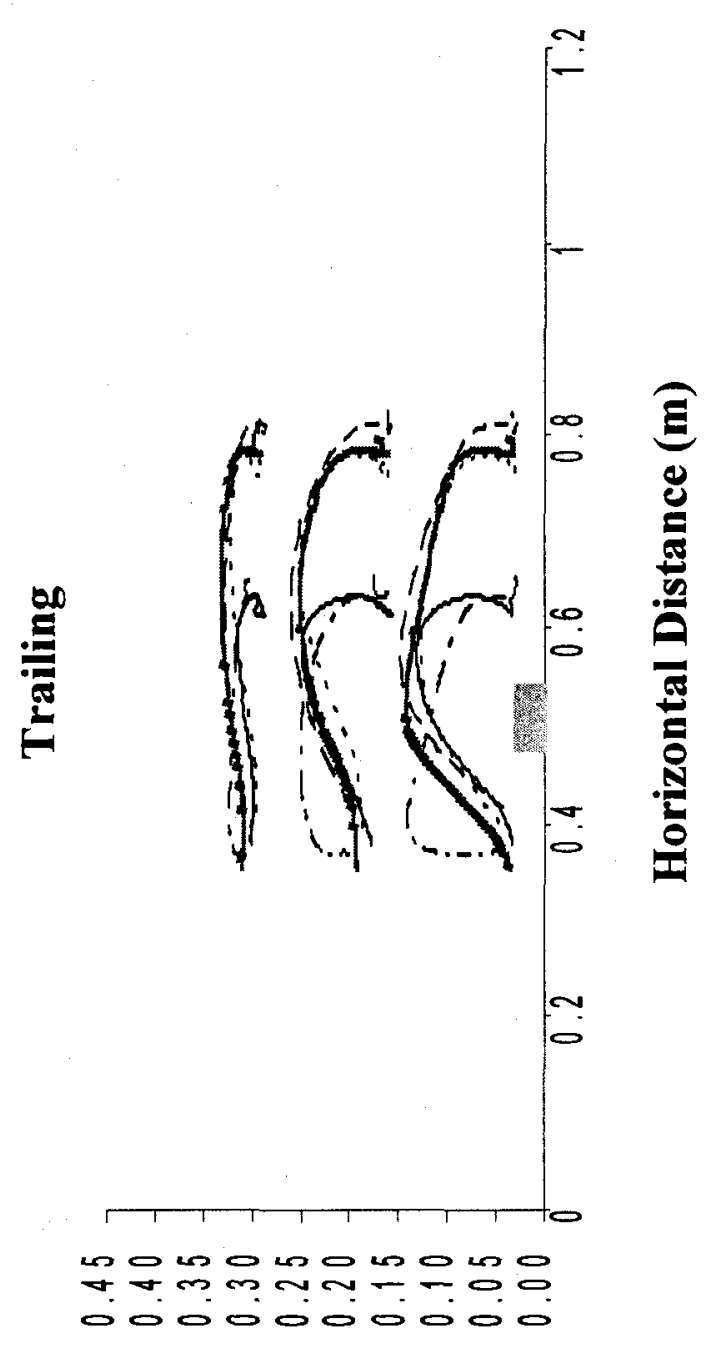

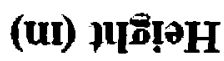




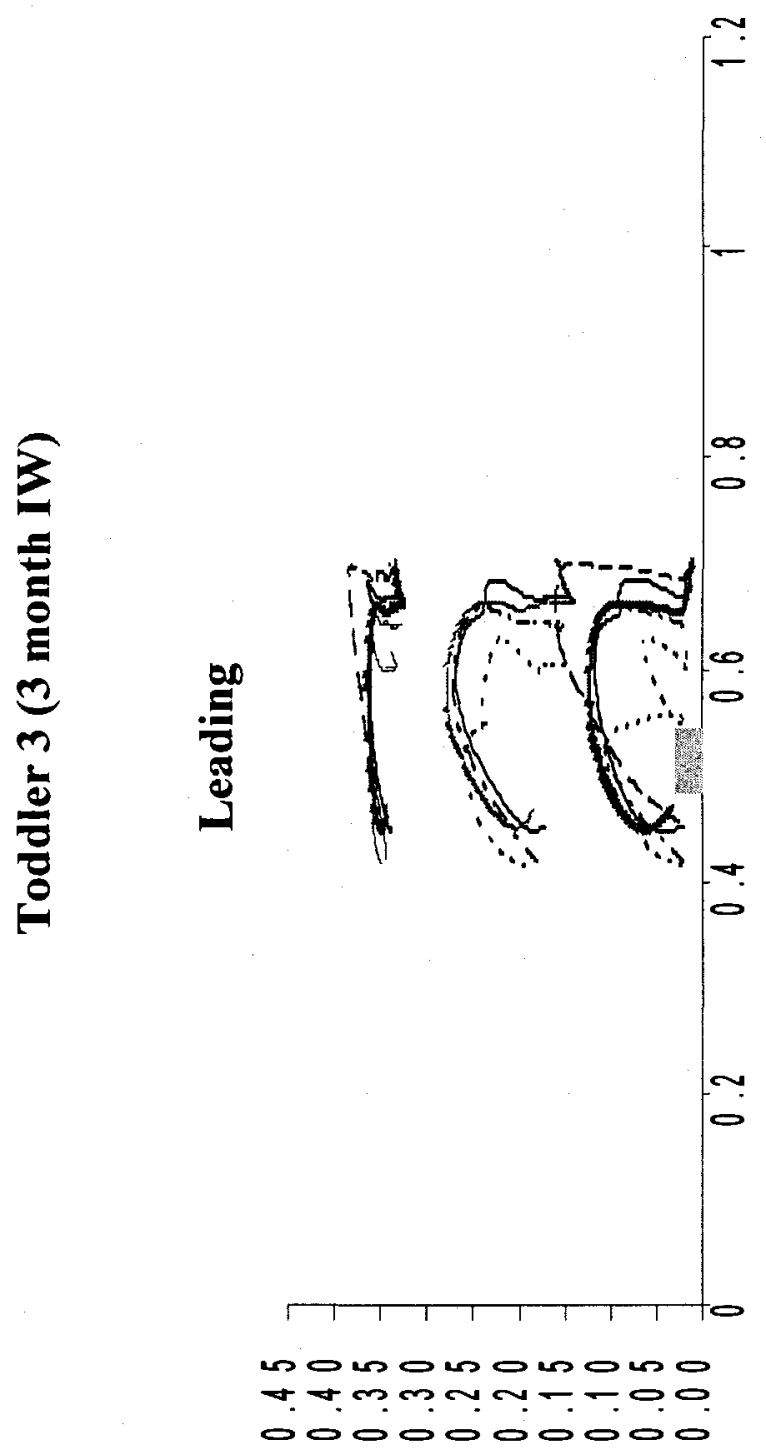

(u) $)$ บธิตฺว

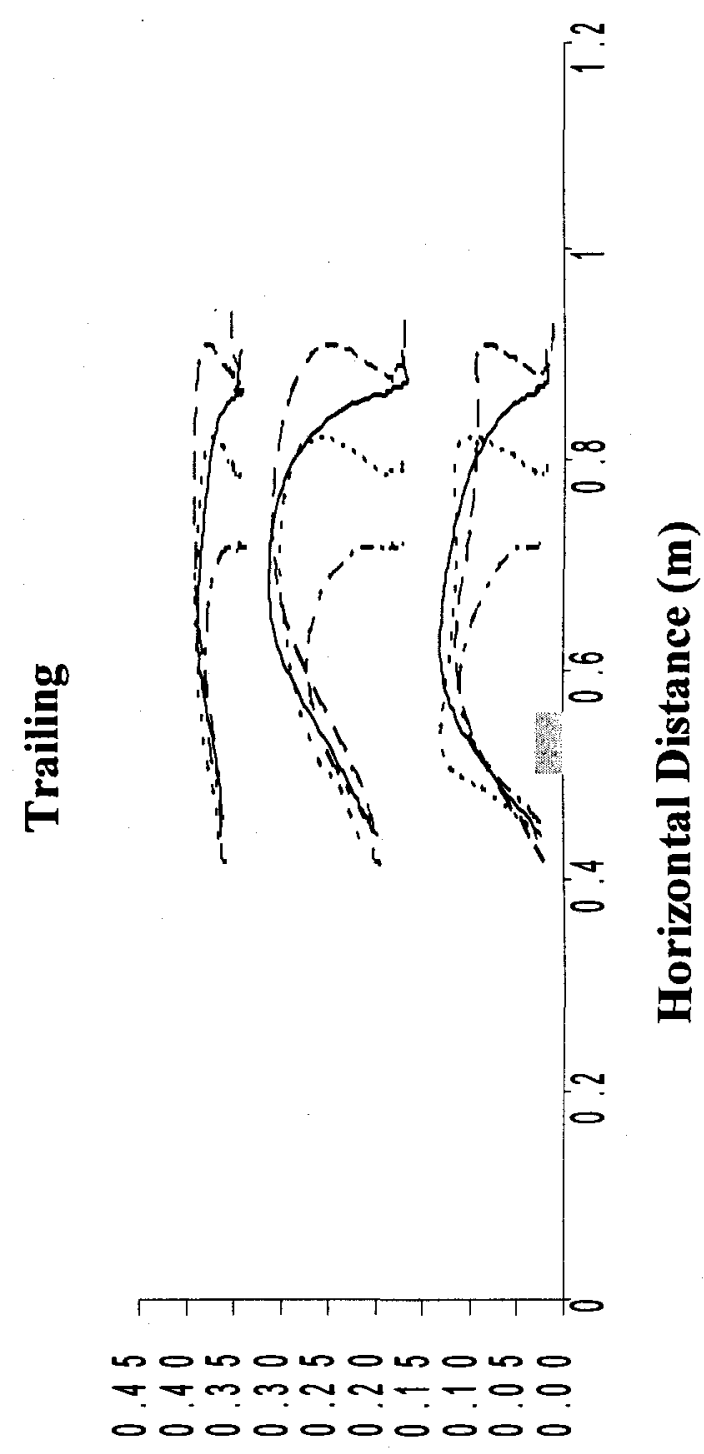

(uI) $\mathcal{1}$ ติเดН 


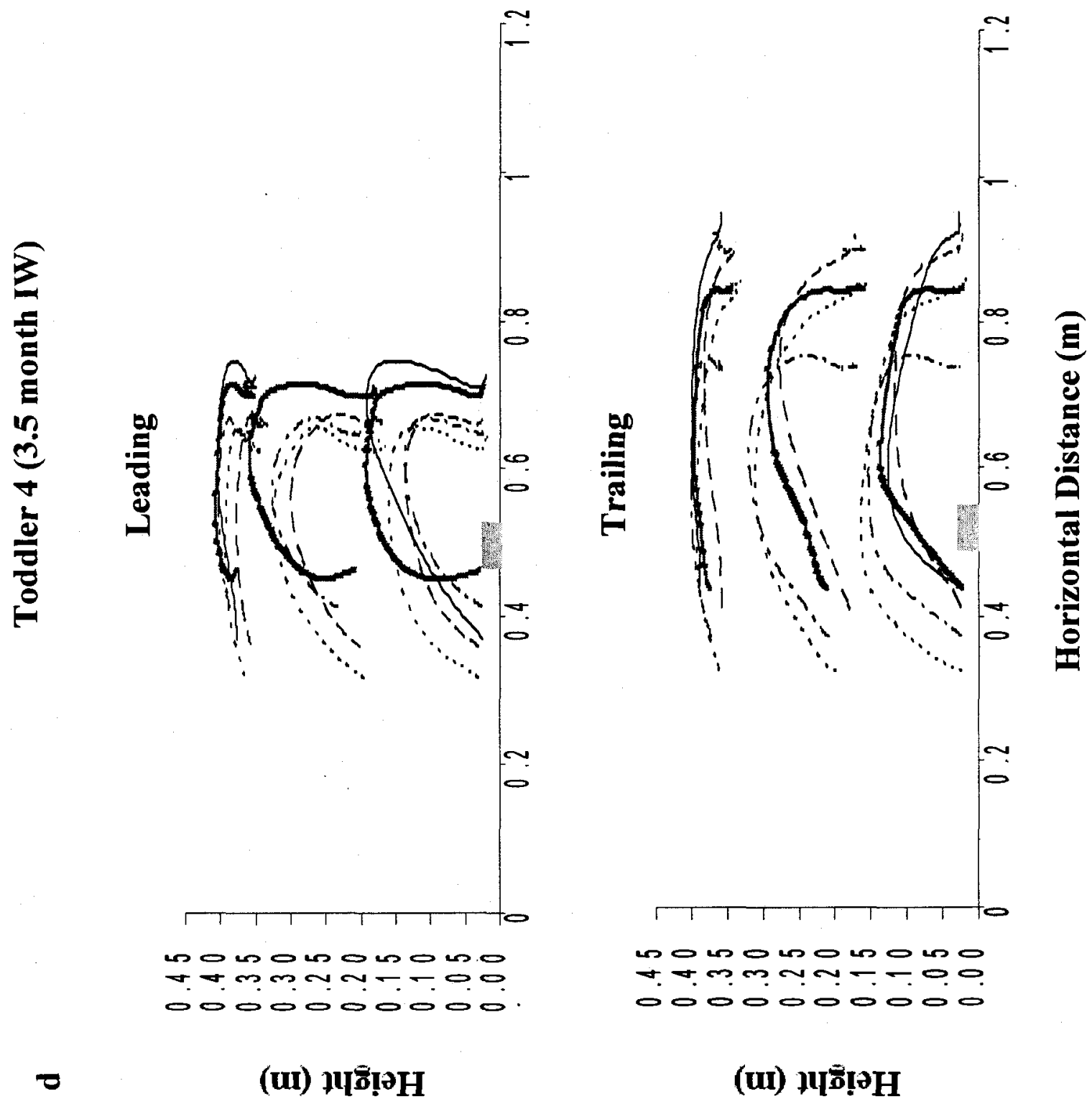




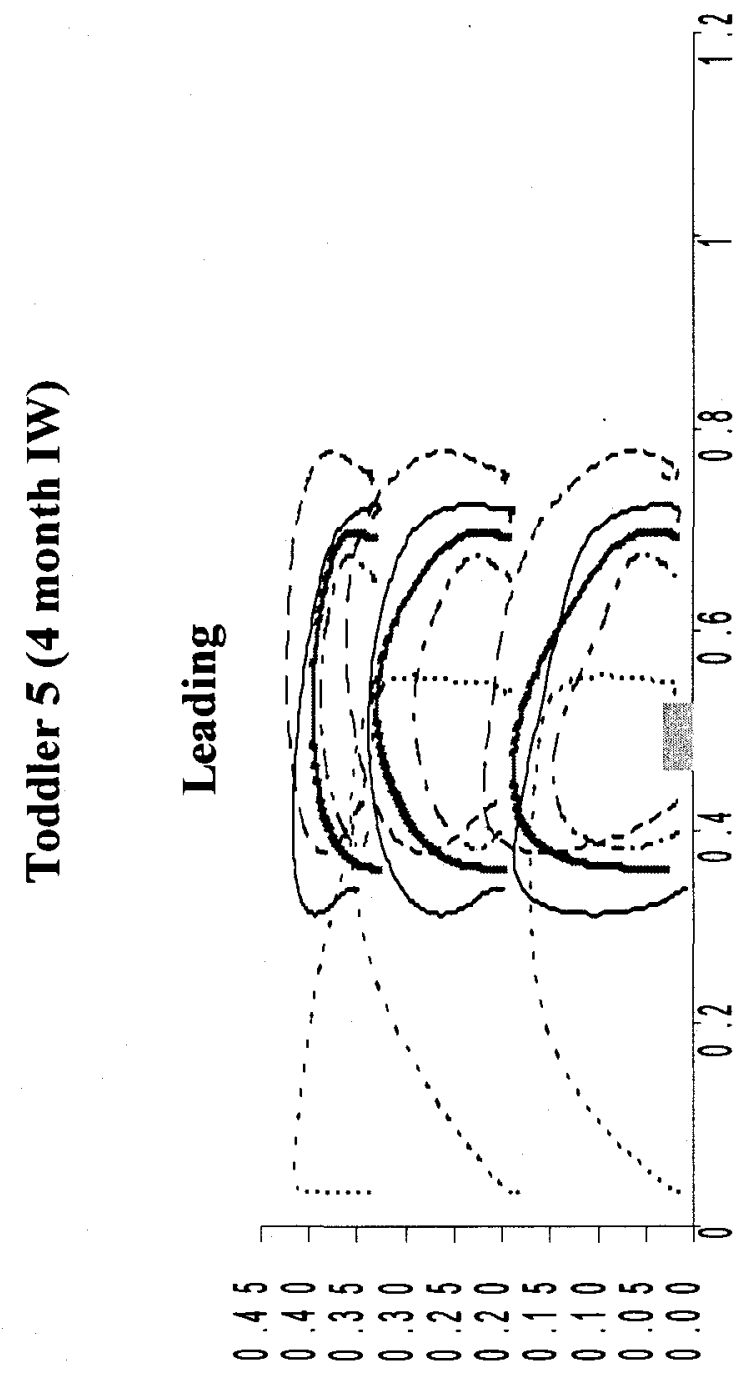

0

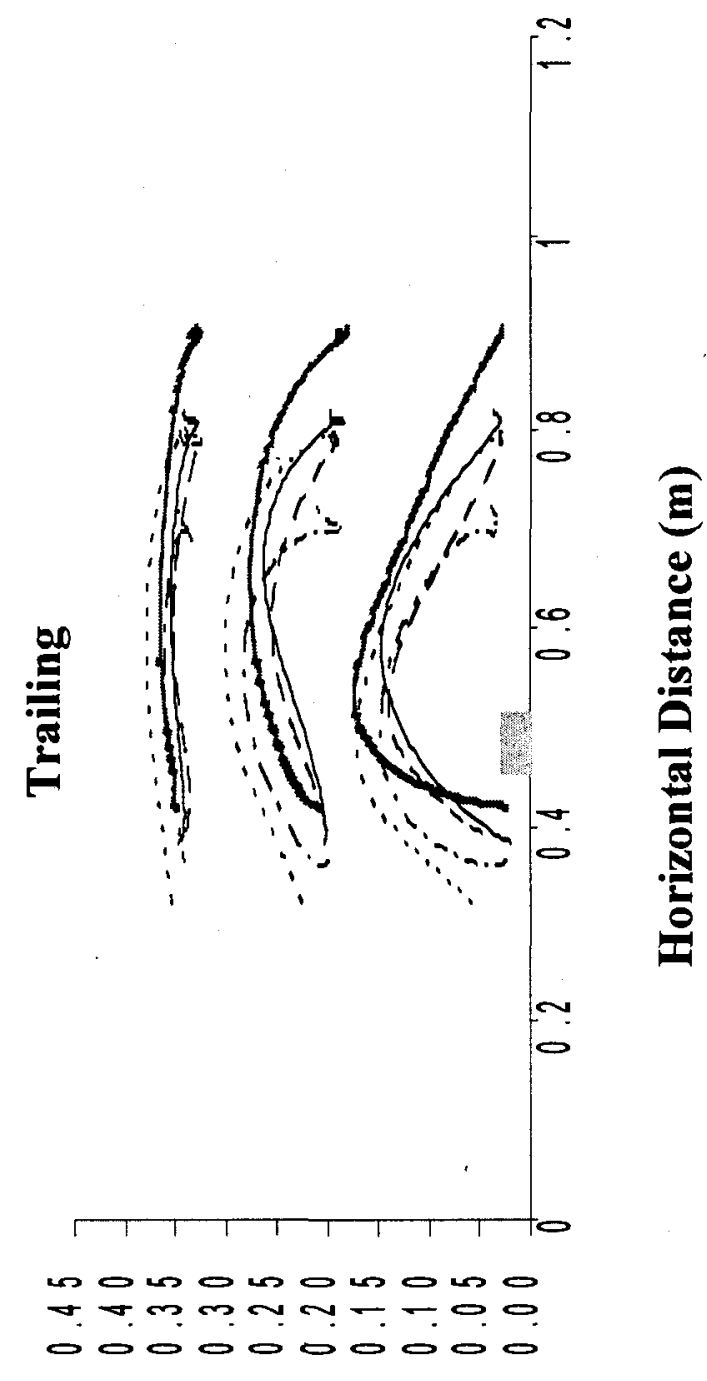

(ui) วบธิเฺ๋ 


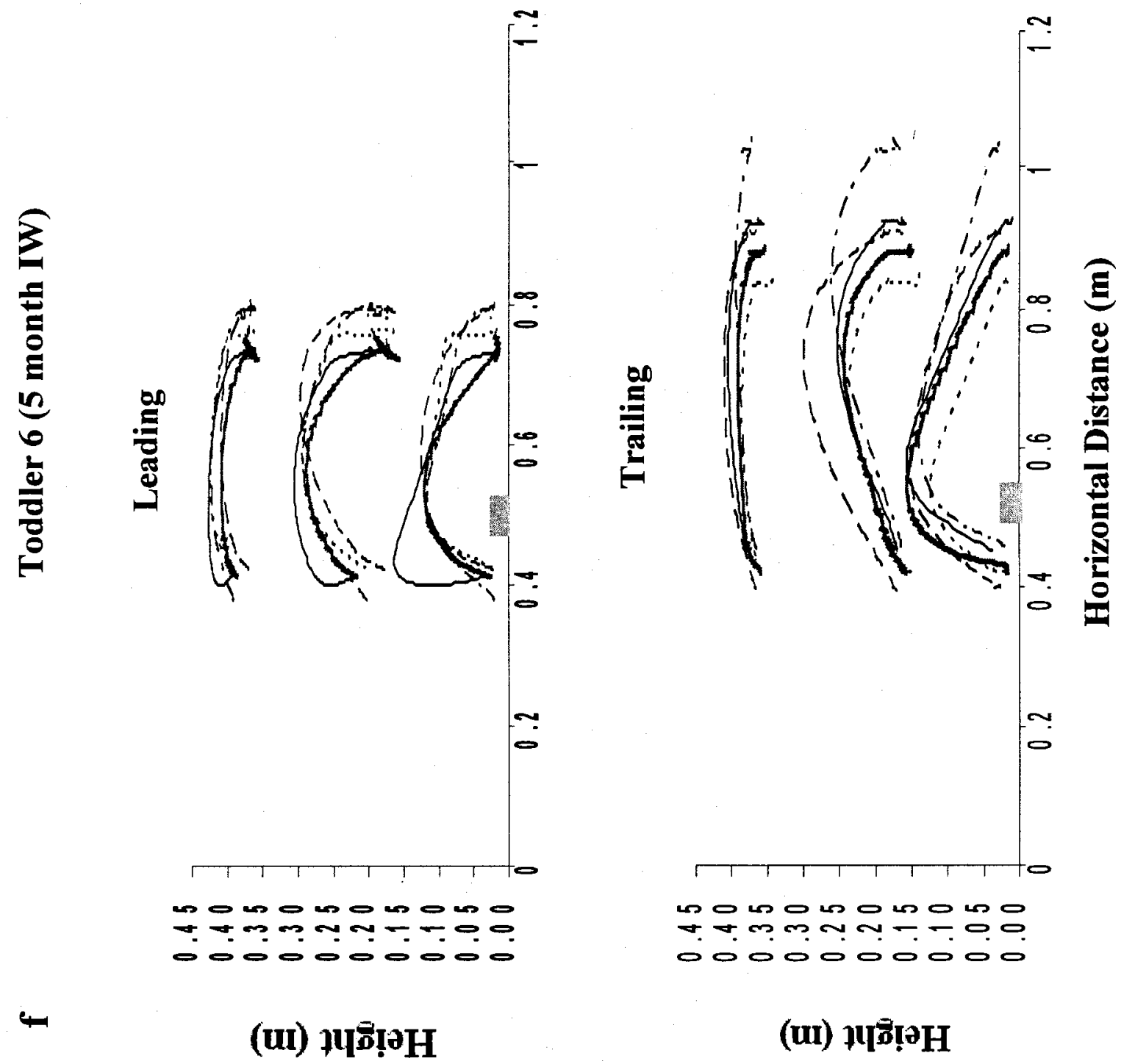




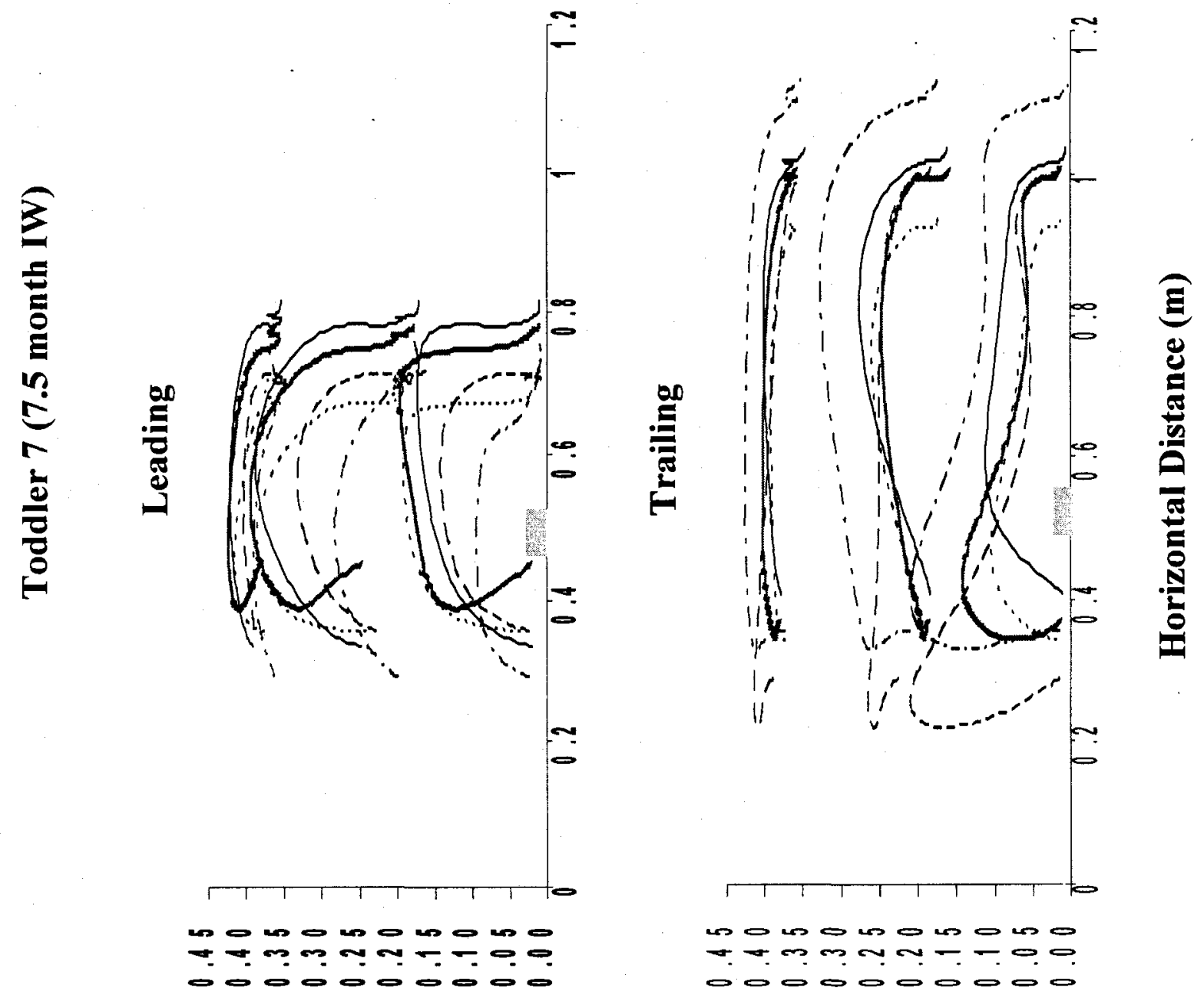




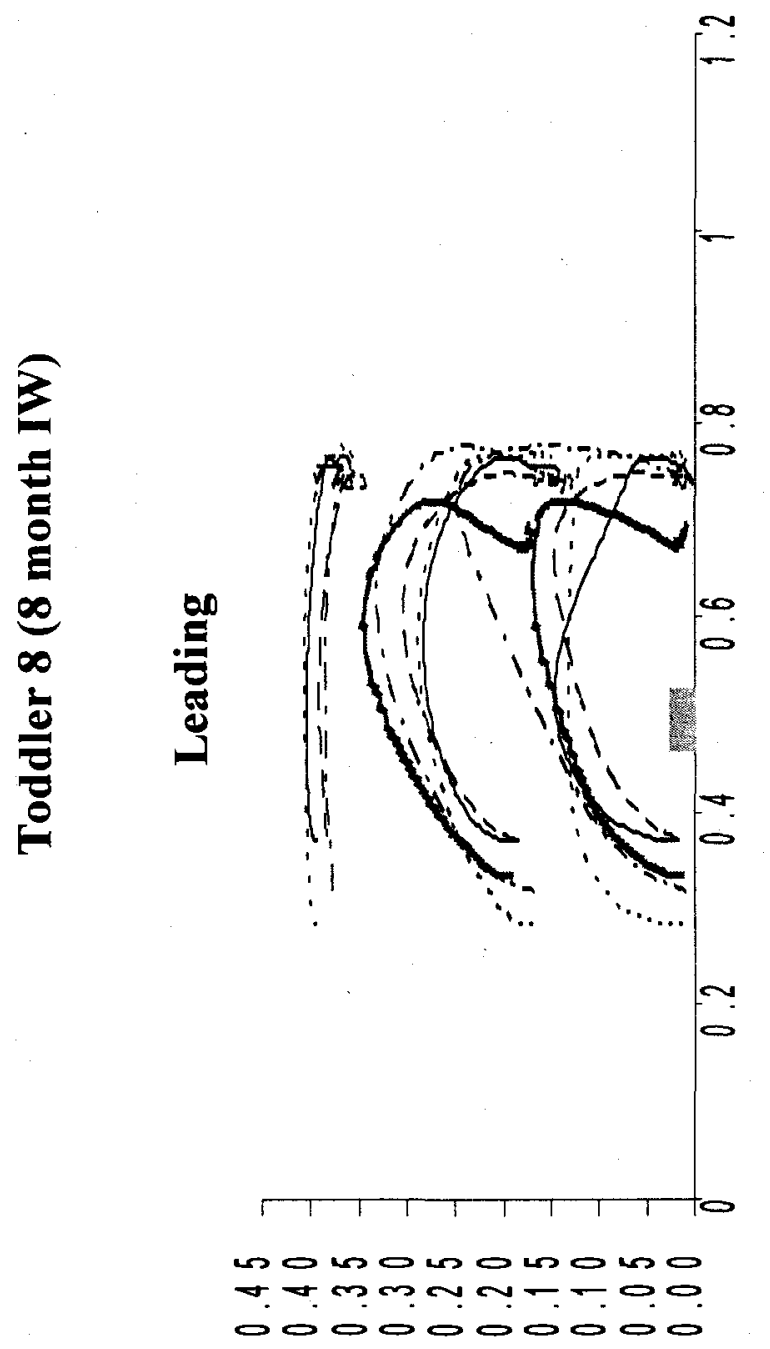

(ui) $\chi$ ำิำH

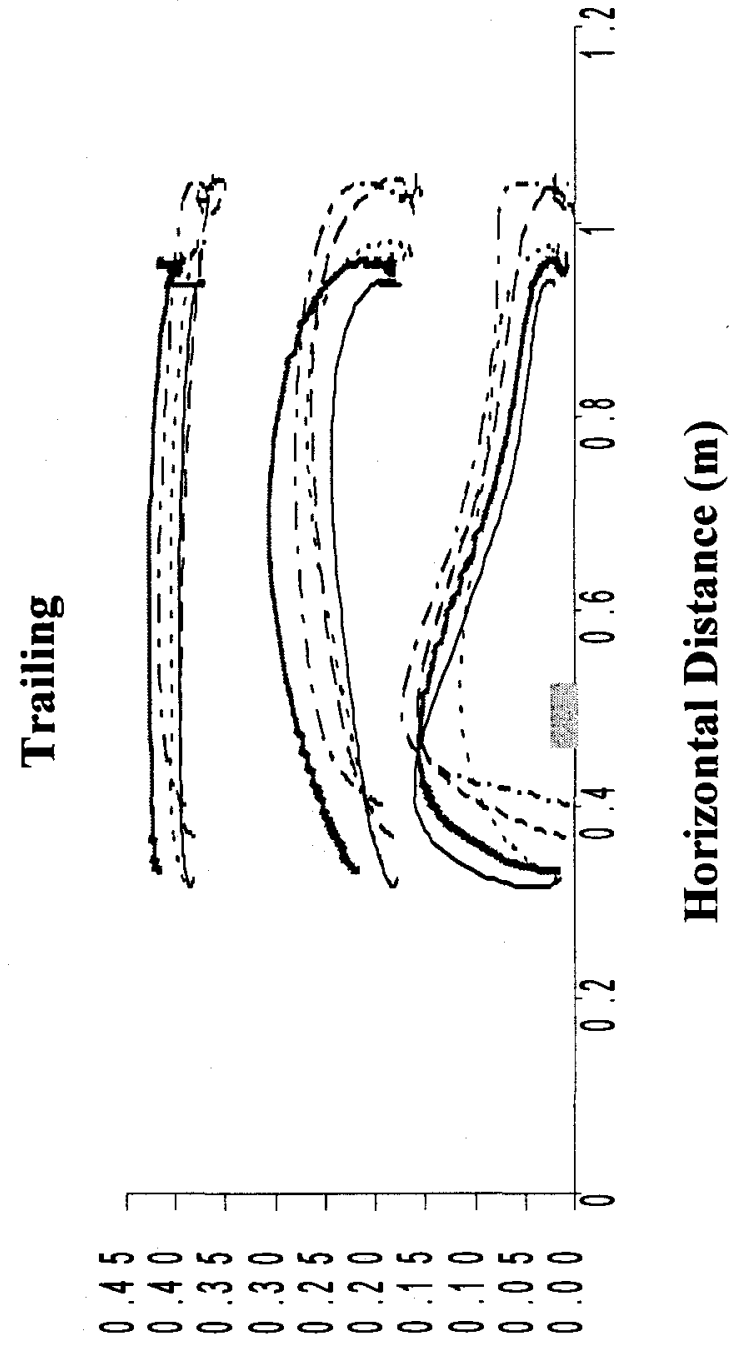

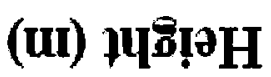

\section{Figure 3. Spatial Trajectories}

The spatial trajectories of the hip, knee and toe of the leading (top panels) and trailing limbs (bottom panels) are plotted for toddlers 1 to $8(a-h)$. Five trials are plotted for each toddler. The gray rectangle represents the obstacle. 
Table 2. OC Success Rate

\begin{tabular}{|c|c|c|c|c|c|c|}
\hline $\begin{array}{c}\text { Age } \\
\text { (months) }\end{array}$ & $\begin{array}{c}\text { Independent } \\
\text { walking } \\
\text { (months) }\end{array}$ & $\begin{array}{c}\text { Total } \\
\text { numbers of } \\
\text { trials }\end{array}$ & $\begin{array}{c}\% \text { trials } \\
\text { where } \\
\text { leading foot } \\
\text { contacted } \\
\text { obstacle }\end{array}$ & $\begin{array}{c}\% \text { trials } \\
\text { where } \\
\text { trailing foot } \\
\text { contacted } \\
\text { obstacle }\end{array}$ & $\%$ clear & $\%$ crawling \\
\hline 15 & 1 & 30 & 57 & 43 & 27 & 10 \\
\hline 15 & 2.5 & 25 & 76 & 24 & 16 & 8 \\
\hline 16 & 3 & 35 & 62 & 31 & 34 & 0 \\
\hline 15 & 3.5 & 23 & 56 & 34 & 35 & 0 \\
\hline 15.5 & 4 & 21 & 42 & 28 & 61 & 0 \\
\hline 18 & 5 & 23 & 34 & 34 & 61 & 0 \\
\hline 17.5 & 7.5 & 23 & 34 & 13 & 70 & 0 \\
\hline
\end{tabular}

Table 2. Success rate in obstacle crossing is shown as a function of increasing months of walking experience. 


\section{Step Length}

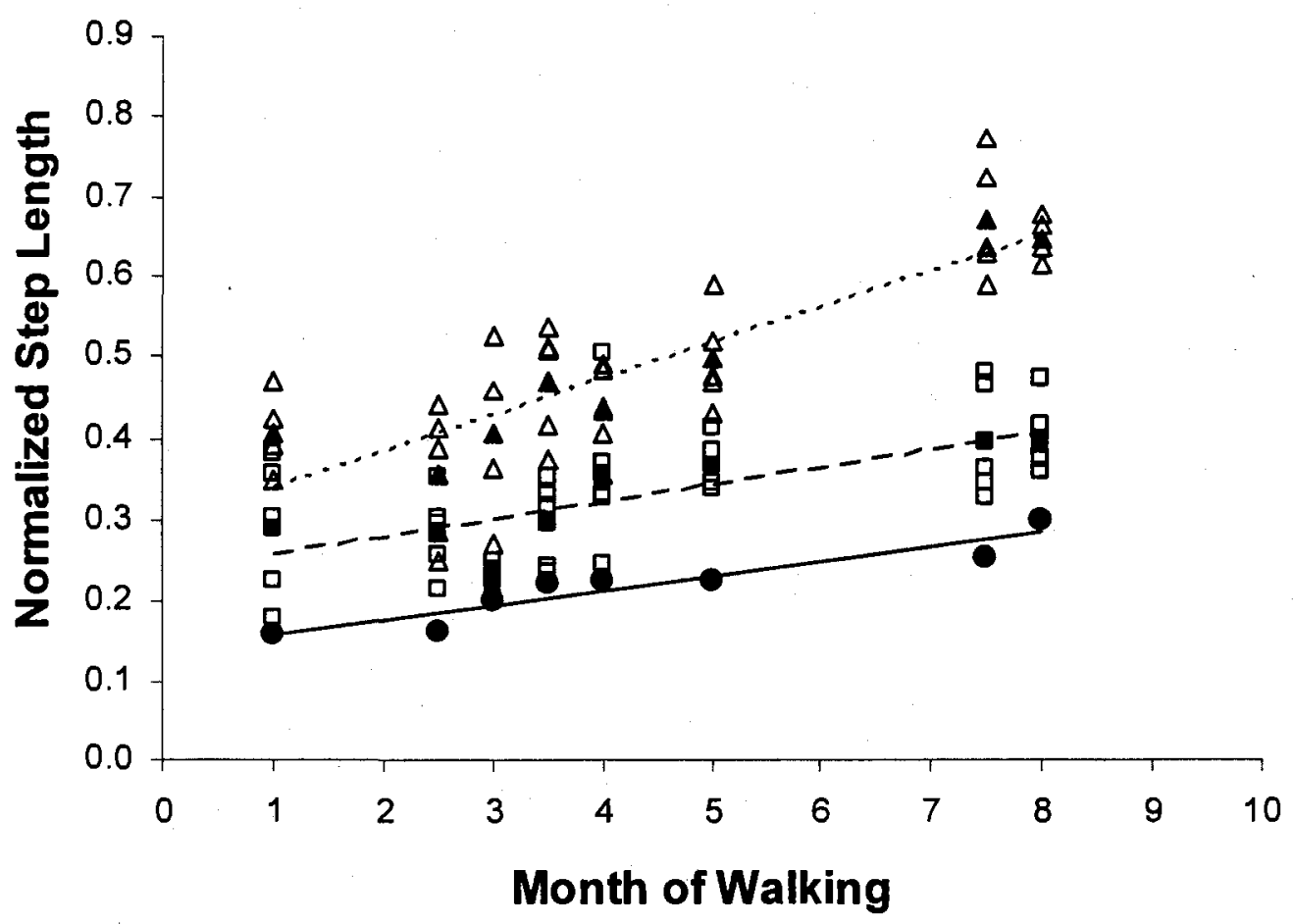

Figure 4. Step Length vs. Month of Walking

The step length of the leading and trailing limb over the obstacle and during unobstructed walking are plotted against months of walking experience. For each toddler, open squares and open triangles represent the step lengths from five obstacle crossing trials of the leading and trailing limb, filled squares and triangles represent the mean step length of the leading and trailing limb, and filled circles represent the mean step length for unobstructed walking. Regression lines are plotted illustrating the relationship of walking experience to trailing limb step length $\left(r^{2}=0.8767\right.$; dotted line $)$, leading limb step length $\left(r^{2}=0.6963\right.$; dashed line) and unobstructed step length $\left(r^{2}=0.8818\right.$; solid line) 
Leading
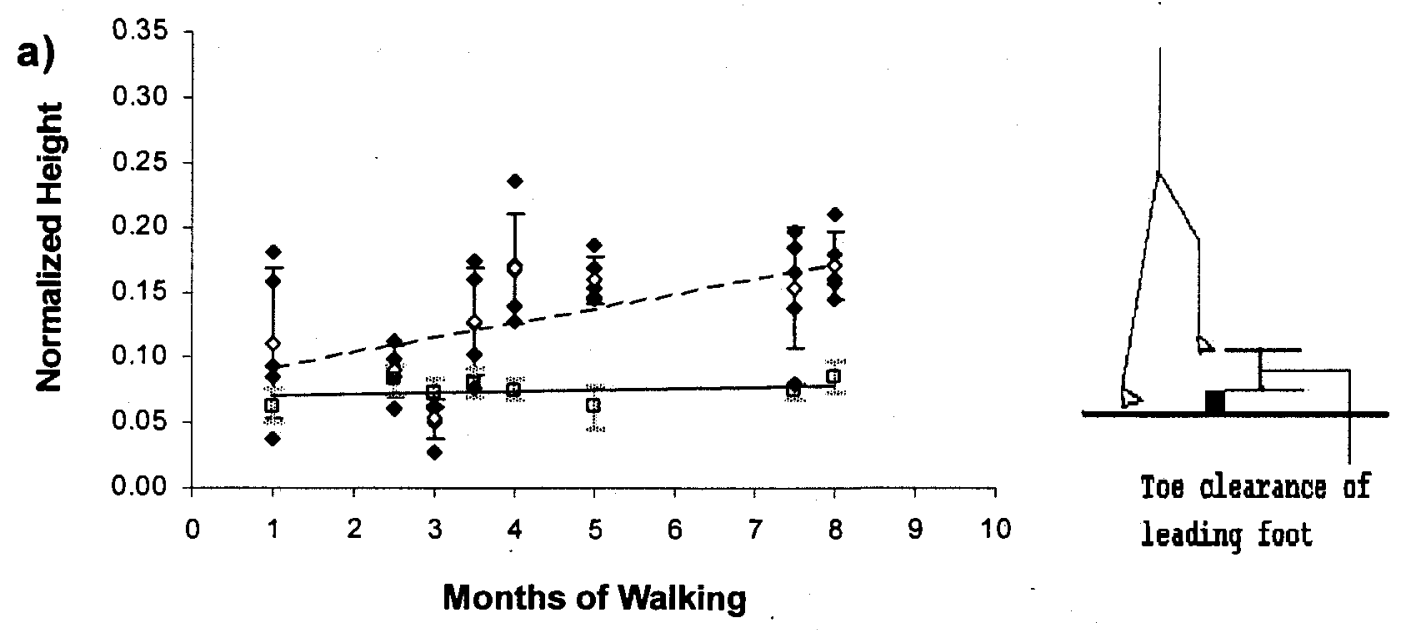

Trailing
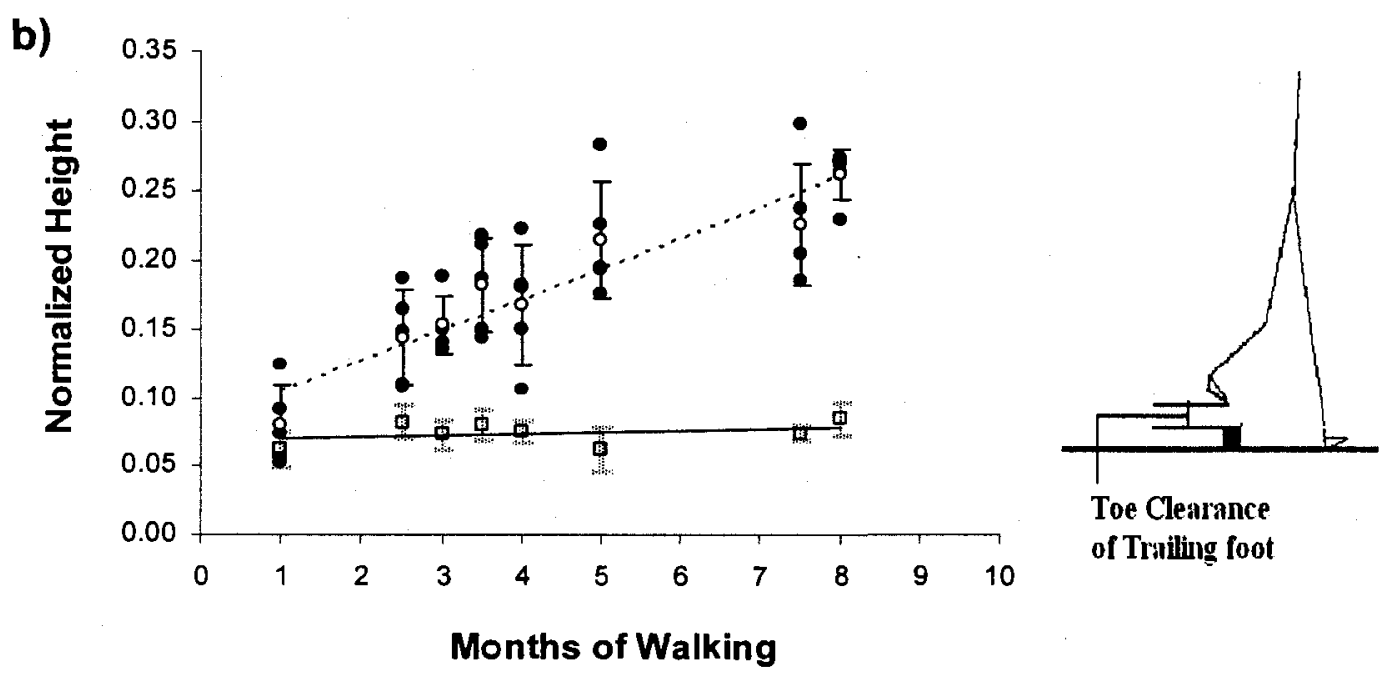

\section{Figure 5. Leading and Trailing Toe Clearance}

Toe clearance height of the leading (top) and trailing (bottom) limbs for five obstacle crossing (filled circles) trials as well as mean values of obstacle crossing (open circles) and unobstructed (open squares) are shown. Regression lines are plotted illustrating the relationship of walking experience to leading and trailing limb toe clearance during obstacle crossing (leading limb $r^{2}=0.536$; trailing limb $r^{2}=0.9039$ : dashed lines) and unobstructed (leading limb $r^{2}=0.1057$; trailing $\operatorname{limb} \mathrm{r}^{2}=0.1156$ : solid lines) conditions. 


\section{Toe and Heel Distance}

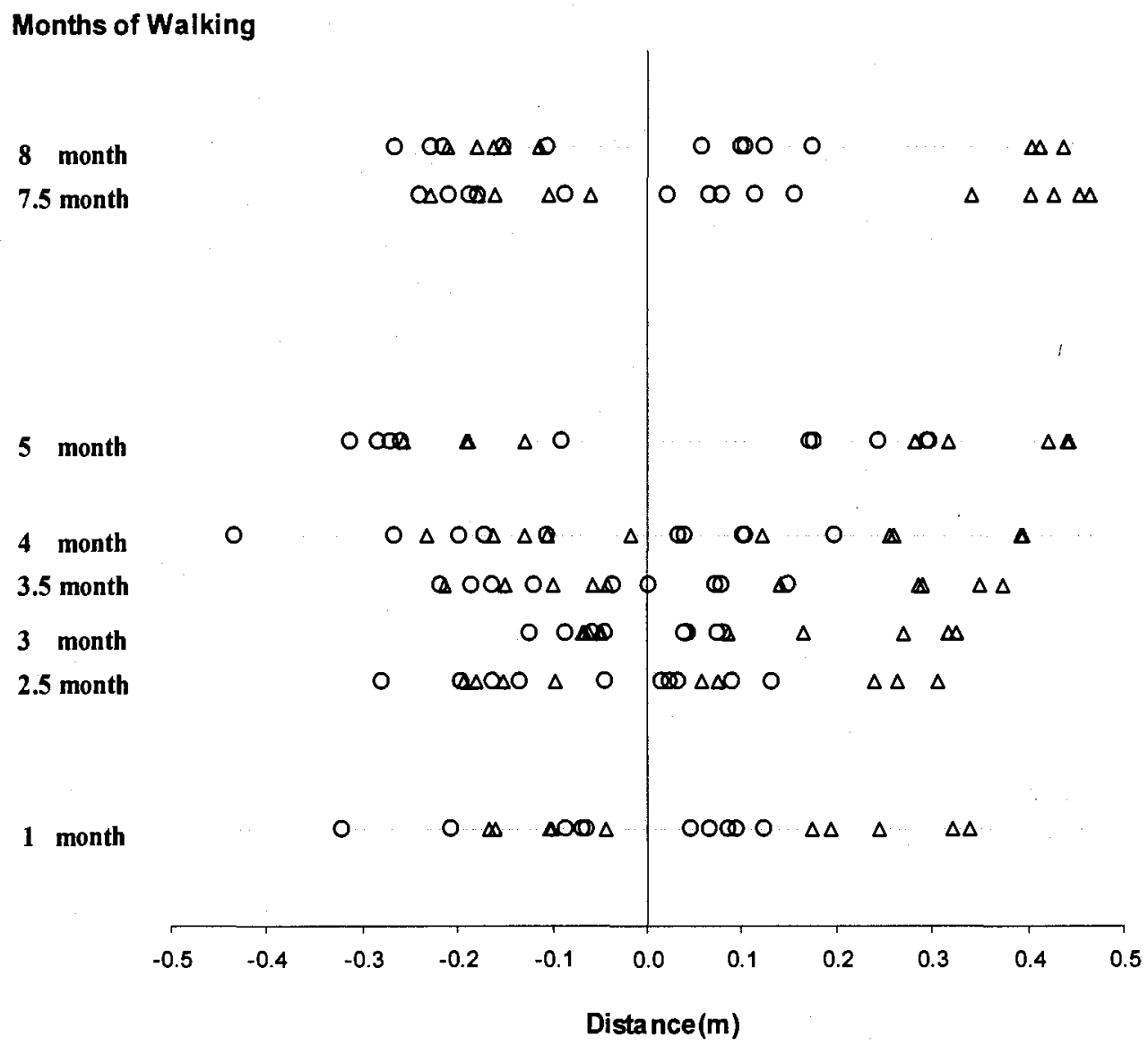

Figure 6. Toe and Heel Distance

Leading (open circles) and trailing limb (open triangles) toe off distances prior to the obstacle and heel contact distances after the obstacle are plotted for eight toddlers against months of walking experience. The vertical line at 0 represents the location of the obstacle. 
Table 3. Leading and Trailing Toe and Heel Distance to Obstacle

\begin{tabular}{|c|c|c|c|c|}
\hline Toddler & $\begin{array}{c}\text { Mean (SD) } \\
\text { Leading TD }\end{array}$ & $\begin{array}{c}\text { Mean (SD) } \\
\text { Trailing TD }\end{array}$ & $\begin{array}{c}\text { Mean (SD) } \\
\text { Leading HD }\end{array}$ & $\begin{array}{c}\text { Mean (SD) } \\
\text { Trailing HD }\end{array}$ \\
\hline 1 & $0.149 \pm 0.101$ & $0.115 \pm 0.051$ & $0.084 \pm 0.026$ & $0.255 \pm 0.074$ \\
\hline 2 & $0.163 \pm 0.077$ & $0.161 \pm 0.039$ & $0.059 \pm 0.045$ & $0.189 \pm 0.115$ \\
\hline 3 & $0.079 \pm 0.027$ & $0.06 \pm 0.01$ & $0.056 \pm 0.018$ & $0.233 \pm 0.104$ \\
\hline 4 & $0.144 \pm 0.064$ & $0.112 \pm 0.07$ & $0.062 \pm 0.055$ & $0.288 \pm 0.091$ \\
\hline 5 & $0.235 \pm 0.112$ & $0.129 \pm 0.079$ & $0.095 \pm 0.059$ & $0.284 \pm 0.114$ \\
\hline 6 & $0.243 \pm 0.079$ & $0.119 \pm 0.053$ & $0.238 \pm 0.055$ & $0.381 \pm 0.076$ \\
\hline 7 & $0.193 \pm 0.058$ & $0.165 \pm 0.035$ & $0.111 \pm 0.038$ & $0.443 \pm 0.051$ \\
\hline 8 & $0.18 \pm 0.052$ & $0.146 \pm 0.066$ & $0.088 \pm 0.045$ & $0.418 \pm 0.049$ \\
\hline $\mathrm{R}^{2}$ & 0.1705 & 0.098 & 0.2302 & 0.8248 \\
\hline
\end{tabular}

Table 3. Toe off distance (TD) to obstacle prior to obstacle. Heel contact distance (HD) to obstacle after obstacle. Regression $\mathrm{R}^{2}$ of mean of leading and trailing TD and HD over months of walking (1-8 month IW) are reported. 
Table 4. Knee Joint Flexion and Hip Joint Extension: Pairwise Comparisons

\begin{tabular}{l|c|c|c}
\hline \multicolumn{1}{c|}{ Comparisons } & $\begin{array}{c}\text { Mean } \pm \\
\text { S.D. }\end{array}$ & $\begin{array}{c}\text { Mean } \pm \\
\text { S.D. }\end{array}$ & Sig. \\
\hline Leading limb \\
\hline Knee joint angle (Obstacle versus unobstructed) & $92 \pm 15$ & $125 \pm 19$ & 0.006 \\
\hline Hip joint angle (Obstacle versus unobstructed) & $127 \pm 15$ & $140 \pm 11$ & 0.001 \\
\hline Trailing limb \\
\hline Knee joint angle (Obstacle versus unobstructed) & $76 \pm 12$ & $125 \pm 19$ & 0.0005 \\
\hline Hip joint angle (Obstacle versus unobstructed) & $133 \pm 13$ & $140 \pm 11$ & 0.035 \\
\hline Leading versus trailing limb \\
\hline Knee joint angle (Obstacle) & $92 \pm 15$ & $76 \pm 12$ & $<0.0005$ \\
\hline Hip joint angle (Obstacle) & $127 \pm 15$ & $133 \pm 13$ & 0.069 \\
\hline
\end{tabular}

Table 4. Pairwise comparisons of leading and trailing limb knee joint flexion and hip joint extension angles during obstacle crossing and unobstructed walking trials. Obstacle refers to joint angle when the toe is directly above the obstacle in obstacle crossing trials. Unobstructed refers to the maximum joint angle during unobstructed walking trials. 


\section{CHAPTER V}

\section{Discussion}

\section{Review}

Environmental information together with sensory inputs trigger the CNS to make the appropriate responses for ensuring safety and efficiency of each movement. When we are moving, postural control systems act to stabilize our body. In self-paced movements, both postural adjustments and voluntary limb movements appear to be parts of the same motor program (Lee et al., 1987; Zattara \& Bouisset, 1988). That said, limb trajectories are influenced by both reactive and anticipatory responses. Reactive responses are induced by sudden environmental changes that would threaten body stability. On the other hand, anticipatory responses are based on mapping orientation of CNS achieved through interaction with various locomotor contexts.

One model of how locomotor adjustments are generated is illustrated using figure 7 below. To generate appropriate responses, well integrated postural control systems established by repetitively performing various motor tasks are required. In order to safely and efficiently accomplish individual locomotor tasks, the sensory-motor system integrates available or learned locomotor responses to cooperate with different magnitudes of adjustments. Postural control systems function in a feed-forward fashion with the supplement of feedback reactions to posture threats. 


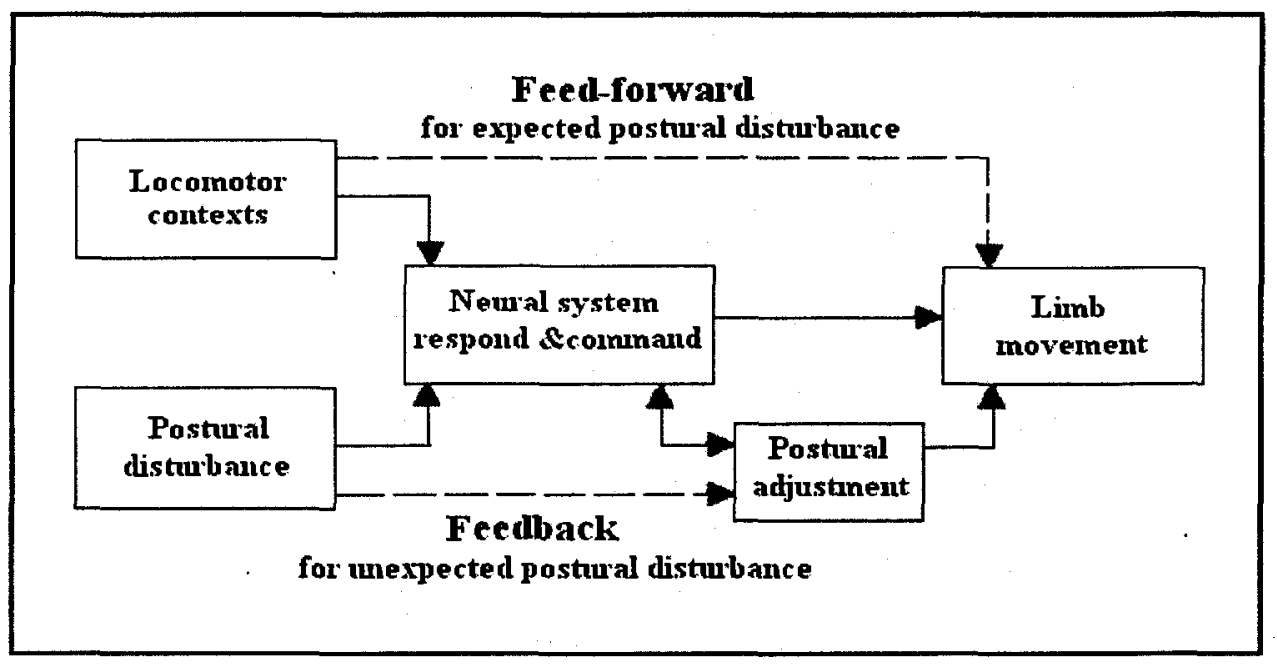

Figure 7. Feed-forward and Feedback Postural Adjustment (adapted from Gahery \& Massion, 1981).

Stepping over obstacle as voluntary behavior requires planned locomotor adjustments to ensure safe circumvention of the obstacle (Patla et al., 1996; Austin et al., 1999; Lu et al., 2006). These adjustments made prior to and over the obstacle are based on the anticipation of the obstacle(s) characteristics, including location, shape and height. Moreover, obstacle height is one of the determinant factors for deciding whether to go over or around obstacles. As reported in previous literatures, TC increases as a function of obstacle height, but decreases at a transition point around $12.6 \mathrm{~cm}$ (approximate $15 \%$ of adults' leg length) obstacle height (Austin et al., 1999). Reduction of TC increased risk of tripping over the obstacle. This was especially true for toddlers, not all toddlers in an obstacle crossing preliminary study were able to go over the $14 \mathrm{~cm}$ height obstacle as reported by Patla (1996). To avoid obstacle height manipulation caused failures, we choose our obstacle to be around $10 \%$ of subject average leg length.

A visible fixed obstacle was used for our experiment; as we hypothesized that a high failure of obstacle circumvention would be unavoidable if randomly presented obstacles were used. This assumption was formed based on performance of adults in negotiating random obstacles. Even adults could not make appropriate adjustments within one step 
length, requiring two step lengths of adjustment time prior to the obstacles (Patla et al., 1991).

The circumvention strategies used by adults are exhibited through changes of locomotor patterns and often described in terms of temporal-distance (e.g., step length, step width), body kinematics (e.g., TC, toe off and heel contact distance,), movement kinetics and lower limb muscle activity.

- In this study, kinematics patterns were used to describe limb trajectories over the obstacle.

\section{Discussion}

As acknowledged in the studies of independent walking (Bril \& Brenerier, 1990; Assainte \& Amblard, 1995; Grasso et al., 1997), postural control is critical to efficient gait maneuver over ground. Development and integration of postural control systems in obstacle negotiation is the interest of this study. Temporal and kinematic parameters were analyzed and characterized for exploring characteristics of postural control related coordination with respect to obstacle negotiation. We hypothesized that 1) compared with unobstructed trials, toddlers would decrease the length of the step crossing an obstacle; 2) compared to unobstructed walking, knee flexion of the leading limb would be significantly greater when stepping over an obstacle; 3) toddlers would produce greater toe clearance over an obstacle compared to that of adults as reported previously in the literature; and 4) toe clearance over an obstacle would decrease from 1 month to 8 months of independent walking.

To ensure our participating toddlers were a good representation of toddlers with 1 to 8 months of independent walking experience, we compared data from the experimental cohort with those from published reports of previous IW studies (Bril \& Breniere, 1992, Sutherland, 1997), which coincided with each other as indicated in Appendix, table 6. Our results are: velocity: $\bar{X}=0.614 \pm 0.162 \mathrm{~m} / \mathrm{s}$ (range: $0.454-0.995 \mathrm{~m} / \mathrm{s}$ ); stride length: $\bar{X}$ $=0.441 \pm 0.093 \mathrm{~m} / \mathrm{s}$ (range: $0.321-0.612 \mathrm{~m} / \mathrm{s}$ ); stride width: $\bar{X}=0.171 \pm 0.118 \mathrm{~m} / \mathrm{s}$ (range: 0.103-0.46 m/s); step length: $\bar{X}=0.219 \pm 0.047$ (range: $0.158-0.301 \mathrm{~m} / \mathrm{s}$ ). The details of unobstructed gait from the experimental cohort are reported in Appendix, table 5. 


\section{Dynamic postural control}

Beginning at birth, children go through a series of motor skill acquisition milestones. A major milestone is marked by the emergence of upright bipedal walking which indicates a completion of the change from static posture to dynamic locomotion. Part of these changes include learning to control posture while moving, specifically walking, is essential for the child's safety as there is greater risk of falling when they are walking. For children, risk factors for falling while walking include lateral body sway, forward propulsion, and one leg supporting during swing phase (Keogh \& Sugden, 1985; Breniere \& Bril, 1989; Winter, 1990; Assaiante et al., 1993). For consistent behavior, dynamic postural control is required for maintaining balance.

The risk of falling increases when toddlers need to circumvent obstacles on the road due to the greater demand for stability. Going over obstacles requires greater forward propulsion as the distance to travel over the obstacles is greater than the distance covered in an unobstructed step (Patla et al., 1996). Moreover, when one leg steps over the obstacle, the contralateral leg must support the whole body mass and counteract the reverse force of forward propulsion. The magnitude of lateral body sway increases as the leg swings over the obstacle and as the leg travels a much longer distance. In addition, the observed obstacle heights influence the decision of whether going over the obstacle made. Therefore, to choose going around rather than over the obstacles would be safer. Similar to older adults who are more likely to avoid the obstacles, when obstacle height is greater than a certain proportion of lower leg length (Konczak et al., 1992; Patla et al., 1996), in this study, toddlers with the least IW experience was also found adopted this preference. It may be because that with lesser control of stability, they would prefer safer and easier alternatives.

Once toddlers decided to step over the obstacles, ensuring safe circumvention became their priority. For adults, consistent and safe obstacle negotiation relies on the anticipation of the obstacle where anticipatory adjustments are made to achieve appropriate take off position and sufficient toe clearance (McFadyen et al., 1993, 2001). Obstacles must be perceived two steps before going over in order to allow adequate time for anticipatory adjustments including postural adjustments to occur (Patla et al., 1991). However, in the 
present study, these anticipatory adjustments were absent, especially for toddlers with 1 to 5 months of IW experience. Specifically, there were no obvious adaptive locomotor patterns found when approaching the obstacle. Both the leading and trailing step length prior to the obstacle were inconsistent between trials. Additionally, similar variability in the take off positions of the leading and trailing feet prior to the obstacle was also recorded. In contrast, toddlers with greater than 5 months IW experience were less variable in terms of step length and toe off distance of the leading foot prior to the obstacle. Compared to the leading toe, the trailing toe distance to the obstacle was even less variable. Additionally, our data supported earlier findings reported by Patla (1995) where the trailing limb was positioned closer to the obstacle than the leading limb (less than $0.16 \mathrm{~m}$ ) thus helping the leading limb crossing over the obstacle.

Toddlers showed poor anticipatory adjustments prior to the obstacle. In order not to trip over, it was found that they employed compensatory actions while stepping over the obstacle. Specifically, their leading and trailing limb trajectory patterns were exhibited dramatically different from those displayed by young adults. To describe limb trajectories when going over the obstacle, one commonly measured parameter is the vertical clearance over the obstacle by the toe. In this study, the ratio of toe clearance between over obstacle and unobstructed walking for toddlers was much greater than that reported for adults (Rietdyk \& Patla, 1993; Patla et al., 1996). This difference suggests that the locomotor pattern for obstacle negotiation in toddlers is not yet mature. In fact, the IW capability for toddlers with this amount of walking experience is still in the process of major development (Bril and Breneire, 1991, 1992; Assaiante, 1995; Grasso et al., 1997).

In addition, obstacle negotiation requires postural control systems to accommodate multiple stability threats. To ensure stability, avoiding tripping or stepping on the obstacle by having a large margin over the obstacle is not sufficient. To maintain (or at least not lose) balance, rapid landing of the leading foot after obstacle crossing is also required. During the leading limb swing phase, the weight shift from the contralateral to ipsilateral limb puts the COM temporarily out of the support base potentially leading to a fall. A rapid landing moves the COM quickly back within the support base reducing the risk for a fall or loss of balance. Compared to adults, the landing position of the toddlers leading toe was closer to 
the obstacle. One possibility is that toddlers try to bring the COM back to support base as quickly as possible for safety. Alternatively, the contralateral limb may lack adequate muscle strength to support whole body mass which forces the ipsilateral limb to land as soon as possible. As stated by Bril and Breneire (1991), during the first year of independent walkers, the single limb support duration is shorter than that of adults in unobstructed walking. These authors suggest that this is due to a lack of muscle strength (Bril \& Breneire, $1989,1991, \& 1992)$.

Similar to studies with adult subjects, all measured variables in obstacle crossing dramatically differed from those obtained and computed in unobstructed walking. Specifically, toddlers displayed greater variability between the two sets of locomotor patterns. The discrepancy suggests that when postural control system can not accommodate the task requirements, compensatory actions have to be taken in feedback fashion to maintain continuous locomotion and balance.

\section{Postural control changes}

Changes in the postural control system occur over time and, in part, parallel the acquisition of various gross and fine motor skills. This process continues through adolescence to early adulthood, involving the development of body segment coordination, synthesis of joint motions of multiple magnitudes, muscle control, and CNS response to the sensory inputs (Horak \& Nashner 1986; Assaiante et al., 1993; Grasso et al., 1997). It is a complicated process for the nervous system to generate different postural responses and these can be categorized into two groups, reactive and anticipatory responses. Depending on the locomotor task undertaken, either one or both of the responses are used to help maintain body balance. For a developed postural control system, the fully integrated control mechanisms are capable of efficiently managing all segments and joints involved to accomplish a locomotor task. Such flexibility enables the body to act appropriately and efficiently.

Based on our observations, the findings of this study provided some insights into postural systems development and its integration during the first year of IW. Although most 
of our data is locomotor context dependent, they can still help us to understand the trend of how postural systems are integrated over this period of time.

\section{Locomotor changes over months of walking}

Safely crossing a fixed obstacle requires anticipation of the obstacle and corresponding locomotor adjustments involving the whole body. In adults, the step length and width and velocity prior to the obstacle crossing decreases in order to prepare for an appropriate leading foot taking off position (Vallis \& McFadyen, 2005). Toe off distance for adults is constant kept at 65\% crossing step length (Patla et al., 1996; Sparrow et al., 1996). In contrast, leading and trailing TD displayed by toddlers is inconsistent, especially in the toddlers with less than 5 months IW experience. These toddlers appear unable to properly position their feet prior to the obstacle. Their step length and velocity prior to the obstacle are also highly variable. These observations seem interrelated. Moreover, younger toddlers only initiated locomotor adjustments one step before the crossing step. It is possible that the earliest IW function in a similar fashion to that of older adults as reported by Patla and colleagues (1996). Specifically, Patla argued that limited vision constraints due to aging resulted in the older adults improperly anticipating the location of the fixed obstacle leading to a lack of appropriate lower extremity adjustment in the steps prior to the obstacle. However, vision differences in children aged 1 to 2 years are limited suggesting that this may not fully explain the differences recorded in the earliest walkers. We also found in our study that toddlers showed the most dramatic. OC skill improvements in the period of 4 to 6 months of IW. This coincides with a period of significant changes in IW development (Bril $\&$ Brenerie, 1992) suggesting an alternative explanation. Because of the similarity between OC and IW development stages, we suggest that the inconsistent toe to obstacle distance results from the total absence of anticipatory control. The lack of an anticipatory response from toddlers during the first IW stage could lead to a misjudgment of location and height of the obstacle and greater chances of stepping on or tripping over the obstacle, hence a much lower success rate. Unlike toddlers in the first stage of IW, toddlers with greater than 5 months of IW experience, showed great success rate. They showed anticipatory changes in their locomotor pattern related to the location and the height of the obstacle and subsequently were able to adjust the limbs before the crossing step (Patla et al., 1991). The 
limb trajectory paths and TD in the more experienced toddlers $(>5$ months walking experience) were more consistent between trials compared to those of earlier walkers. These changes suggested that the anticipatory locomotor adaptations to the visible obstacle were better established and less compensatory actions were required resulting in limb trajectories of the crossing step that were closer to those of adults.

In the first year of IW, stability is enhanced by three factors: postural anticipation and reaction to postural disturbances, changing body mass distribution and rapid increases of muscle strength. In particular, during first 5 month of IW, feedforward control emerges; leg strength improves; and the ratio of upper to lower body mass gradually decreases (Bril \& Breneire, 1989, 1991, 1992). These developments allow the lower extremities to provide better single support against gravity and sustain the whole body during obstacle crossing. As observed, obstacle crossing step length, leading and trailing foot landing distance and TC all increased as IW experience increased. This suggests that the support limb was able to provide longer support ensuring body stability. In contrast to our initial hypothesis, the increase in TC with walking experience also makes sense as this increase results in a reduction of the chances of stepping on or tripping over the obstacle. One could rightfully argue that higher TC is not an energy economic solution. In fact, we propose that in contrast to adults, toddlers deploy more conservative strategies to ensure safety and stability rather than optimizing energy efficiency. As evidence, unlike adults, hip elevation is not used by toddlers to achieve sufficient toe clearance since this would result in destabilizing the mass of the whole upper body. We propose that ensuring stability is the initial priority for OC and that only after multiple levels of response are achieved (anticipatory as well as reactive) do safety and energy economy become equally important in the locomotor context. This has been speculated to occur only after the postural control system is fully developed (Grasso et al., 1997).

The findings from the current study suggest that the focus of development during the first year of IW is to achieve a stable locomotion when encountering different locomotor contexts. We further hypothesize that this trend should continue until age of 4 to 5 years of age corresponding to second stage of IW development (Bril \& Breneire, 1990, 1991, 1992) 
at which point energy economy would emerge as critical as safety. This hypothesis must be confirmed by further studies of $\mathrm{OC}$ in children.

Integration of postural control systems

The integration of posture and locomotion initialized from beginning up to 5 months of IW (Bril \& Breneire, 1990). Coinciding with this development, OC behavior continuously changes. We observed that, along with increased walking experience, limb trajectory patterns over the obstacle become increasingly similar to those of adults and OC patterns are increasingly consistent. Four to six months of IW seems to be the dividing point where radical improvements were shown.

The integration of posture and locomotion for performing the $\mathrm{OC}$ task is a gradual and continuous process. The one month independent walkers occasionally would decide to crawl rather than walk over the obstacle. In addition, very inconsistent limb trajectories were displayed. After 1 to 2 months of IW, limb trajectory patterns became more regular, but still remained different from those of adults. With additional walking experience, OC patterns became increasingly similar to those of adults. This suggests that even though sensory stimulation based reactions are generated in neural system at same time, integration of these reactions takes a much longer period of time. Toddler performances of locomotor tasks are very much development phase dependent. We also speculate that this integration process would also be observable from other locomotor contexts

Additionally, integration of different postural reactions (anticipatory and reactive) is dependent on locomotor contexts. In the CNS, neural connections generate complicated motor responses stimulated by afferent inputs. These responses are filtered and modified on the basis of sensory input. Subsequently, muscle activity to maintain posture is produced (Era et al., 1996). The experience based motor responses utilize all available sensory input and integrate accordingly. Based on the locomotor pattern difference between unobstructed walking and obstacle crossing in toddlers, it suggested that how motor responses integrated is triggered by different locomotor contexts. In other words, integration of the postural control is established in a flexible manner. 
As stated by Bril and Breniere (1990), integration of posture and movement for IW is complete around 4 to 6 months of IW with further refinement with additional experience. As soon as toddlers commence IW, they are also exposed to cluttered terrains. Our findings suggest that the integration of posture and movement for obstacle avoidance parallels that of unobstructed walking. We believe that the generation of reactions to these two locomotor tasks would begin almost simultaneously. 


\section{Chapter VI}

\section{Conclusion}

This study focussed on the development of IW within a particular locomotor context, obstacle crossing. Locomotor changes as a function of walking experience were described through analysis of kinematic variables.

The data show that the knee of the leading limb exhibited significantly greater amounts of flexion when stepping over an obstacle compared with unobstructed trials. Furthermore, knee flexion assisted toe clearance over the obstacle was greater in magnitude than unobstructed walking. Interestingly, in comparison with adults, the ratio of toe clearance between over the obstacle and unobstructed walking was greater in toddlers and speculated to be due to immature postural control. These findings verified in part of our hypotheses. In contrast to our original hypotheses, toe clearance over the obstacle increased with walking experience. In addition, the crossing step length was greater over the obstacle compared to unobstructed walking.

However, it remains unclear whether similar changes would be found for other locomotor tasks. Further investigation with regard to the development and integration of postural control in relation to other daily locomotor tasks is still required. 


\section{References:}

Ariun A.S. \& Latash M.L. Directional specificity of postural muscles in feed-forward postural reactions during fast voluntary arm movements. Experimental Brain Research 103: 323-332, 1995

Assaiante C. \& Amblard B. Ontogenesis of head stabilization in space during locomotion in children: influence of visual cues. Experimental Brain Research 93: 499-515, 1993

Assaiante, C., Thomachot, B. \& Aurenty, R. Hip stabilization and lateral balance control in toddlers during the first four months of autonomous walking. NeuroReport 4: 875878,1993

Assaiante C. \& Amblard B. An ontogenetic model for the sensorimotor organization of balance control in humans. Human Movement Science 14: 13-43, 1995

Austin G.P., Garrett G.E., \& Bohannon R.W. Kinematic analysis of obstacle clearance during locomotion. Gait and Posture 10: 109-120, 1999

Baloh R.W., Jacobson K.M. \& Socotch T.M. The effect of ageing on visual-vestibuloocular responses. Experimental Brain Research 95: 509-516, 1993

Begg R.K., Sparrow W.A., \& Lythgo N.D. Time-domain analysis of foot-ground reaction forces in negotiating obstacles. Gait and Posture 7: 99-109, 1998

Beck R., Andriacchi T., Kuo K., Fermier R., \& Galante J. Changes in the gait pattern of growing children. The Journal of Bone and Joint Surgery 63A: 1452-1456, 1981

Bellos A., Carpenter M.G., \& Patla A.E. Strategies for stepping over obstacles: backward stepping is similar to forward trailing limb stepping. Paper presented at International Society for Biomechanics Conference, Vancouver 1996 
Berard J.R. \& Vallis L.A. Characteristics of single and double obstacle avoidance strategies: a comparison between adults and children. Experimental Brain Research 175: 21-31, 2006

Berger W., Quintern J., \& Dietz V. Pathophysiology of gait in children with cerebral palsy. Electroencephalography and Clinical Neurophysiology 53: 538-548, 1982

Bernstein N. The coordination and regulation of movements. Oxford, London: Pergamon Press: $196 \mathrm{pp}, 1967$

Berthoz A. \& Viaud-Delmon. Multisensory integration in spatial orientation. Current Opinion in Neurobiology 9: 708-712, 1999

Bouisset S. \& Zttara M. A sequence of postural movements precedes voluntary movement. Neuroscience Letter 22: 263-270, 1981

Brandt T., Paulus W. \& Straube A. Vision and posture. In: Bles W, Brandt T (Eds.) Disorders of posture and gait. Amsterdam. Elsevier 157-175 pp, 1986

Breniere Y., Bril B., \& Fontaine R. Analysis of the transition from upright stance to steady state locomotion for children under 200 days of autonomous walking. Journal of Motor Behavior 21: 20-37, 1989

Bril B. \& Breniere Y. Steady state velocity and temporal structure of gait during the first six months of autonomous walking. Human Movement Science 8: 99-122, 1989

Bril B. \& Breniere Y. How does the children modulate his progression velocity during the first 18 months of independent walking? In T. Brandt, W Bles \& M. Dietrich (Eds.), disorder of Posture and Gait, 233-236 pp Stuttgart: Georg Thieme Verlag, 1990

Bril B. \& Breniere Y. Timing invariances in toddlers' gait. In J. Fagard \& P. H. Wolff, The development of timing control and temporal organization in coordinated action 231244 pp Amsterdam: North Holland, 1991 
Bril B. \& Breniere Y. Postural requirements and progression velocity in young walkers. Journal of Motor Behavior 24: 105-116, 1992

Bril B. \& Breniere Y. Posture and Independent Locomotion in Early Childhood: Learning to walk or learning dynamic postural control. The development of Coordination in Infancy, Advances in Psychology series, North Holland, 1993

Burnett C.N. \& Johnson E.W. Development of gait in children. Part I: Method. Developmental Medcine and Child Neurology 13: 192-206, 1971

Chen H-L. \& Lu T-W. Comparison of the joint moments between leadinga nd trailing limb in young adults when stepping over obstacles. Gait \& Posture 23: 69-77, 2006

Chen H.C. Ashton-Miller J.A. Alexander N.B. Schultz A.B. Stepping over obstacles: gait patterns of healthy young and old adults. Journal of Gerontology 46(6): 196-203, 1991

Chou L.S. \& Draganich L.F. Stepping over an obstacle increases the motions and moments of the joints of the trailing limb in young adults. Journal of Biomechanics 30(4): $331-7,1996$

Chou L.S., Draganich L.F., \& Song S-H. Minimum energy trajectories of the swing ankle when stepping over obstacles of different heights. Journal of Biomechanics 30: 115120, 1997

Chou L.S. \& Draganich L.F. Placing the trailing foot closer to an obstacle reduces flexion of the hip, knee, and ankle to increase the risk of tripping. Journal of Biomechanics 31 : $685-691,1998$

Chou L.-S., Kaufman K.R., Brey R.H. \& Draganich L.F. Motion of the whole body's center of mass when stepping over obstacles of different heights. Gait \& Posture 13: 17-26, 2001 
Chou L.-S., Kaufman K.R., Hahn M.E., \& Brey R.H. Medio-lateral motion of the centre of mass during obstacle crossing distinguishes elderly individuals with imbalance. Gait \& Posture 18: 125-133, 2003

Clark J.E., Whitall J., \& Phillips S.J. The first 6 months of independent walking. Development of Psychobiology 21: 445-456, 1988

Dietz V. Human neuronal control of automatic functional movements: interaction between central programs and afferent input. Physiological Reviews 72: 33-39, 1992

Dietz V. Neurophysiology of gait disorders: present and future applications. Electroencephalography and Clinical Neurophysiology 103: 333-355, 1997

Draganich L.F., Zacny J., Klafta J. \& Karrison T. The effects of antidepressants on obstructed and unobstructed gait in healthy elderly people. Journals of Gerontology Series A-Biological Sciences \& Medical Sciences 56(1): 36-41, 2001

Era P., Schroll M., Ytting H., Gause-Nilsson I., Heikkinen E. \& Steen B. Postural balance and its sensory - motor correlates in 75-year-old men and women: A cross-national comparative study. Journals of Gerontology Series A: Biological Sciences and Medical Sciences 51A: 53-63, 1996

Eng J.J., Winter D.A., \& Petal A.E. Strategies for recovery from a trip in early and late swing during human walking. Experimental Brain Research 102: 339-349, 1994

Fentress J. The development of coordination. Journal of Motor Behavior 16: 99-134, 1984

Forssberg H. \& Wallberg H. Infant locomotion: A preliminary movement and electromyographic study. In K. Berg \& B. Eriksson (Eds.) Children and exercise $L X$, 32-40 pp. Baltimore: University Park Press, 1980

Forssberg H. Ontogeny of human locomotor control I. Infant stepping, supported locomotion and transition to independent locomotion. Experimental Brain Research 57: 490-493, 1985 
Gahery Y. \& Massion J. Coordination between posture and movement. Trends in Neurosciences 4: 199-202, 1981

Gesell A. The embryology of behavior. New York, Harper, 1945

Gorton G.E., Stevens C.M., Masso P.D., \& Vannah W.M. Repeatability of the walking patterns of normal children. Gait and Posture 5: 155, 1997

Grasso R., Assaiante C., Prévost P. \& Berthoz A. Development of anticipatory orientation strategies during locomotion tasks in children. Neuroscience and biobehavioral Reviews 22: 553-539, 1998

Hahn M.E. \& Chou L.-S. Age-related reduction in sagittal plane center of mass motion during obstacle crossing. Journal of Biomechanics 37: 837-844, 2004

Hill S.W. \& Patla A.E. Indication of Dynamic stability during obstacle avoidance in unilateral below-knee amputees. Paper presented in twenty-second annual conference of the American society of biomechanics, 1998

Hill S.W., Patla A.E., Ishac M.G., Adkin A.L., Supan T.J. \& Barth D.G. Altered kinetic strategy for the control of swing limb elevation over obstacles in unilateral belowknee amputee gait. Journal of Biomechanics 32: 545-549, 1999

Horak F.B. \& Nashner L.M. Central programming of postural movements: Adaptation to altered support-surface configurations. Journal of Neurophysiology 55: 1369-1381, 1986

Keogh J. \& Sugden D. Movement skill development. New York, Macmillan, 1985

Kovacs C. \& Williams K. Sensory training effects on obstacle avoidance in healthy older adults. Physical \& Occupational Therapy in Geriatrics 22: 1-17, 2004

Krell J. \& Patla A.E. The influence of multiple obstacles in the travel path on avoidance strategy. Gait \& Posture 16: 15-19, 2002 
Lee D. \& Aronson E. Visual propriorceptive control of standing in human infants. Perception \& Psychophysics 15: 529-532, 1974

Lee W.A., Buchanan T.S., \& Rogers M.W. Effects of arm acceleration and behavioral conditions on the organization of postural adjustments during arm flexion. Experimental Brain Research 66: 257-270, 1987

Leibowitz H.W., Rodemer C.S., \& Dichgans J. The independence of dynamic spatial orientation from luminance and refractive error. Perception \& Psychophysics 25: 75 79, 1979

Lu T-W., Chen H-L., \& Chen S-C. Comparison of the lower limb kinematics between young and older adults when crossing obstacles of different heights. Gait \& Posture 23: 471-479, 2006

McFadyen B.J. \& Winter D.A. Anticipatory locomotor adjustments during obstructed human walking. Neuroscience Research Communications 9: 37-44, 1991

McFadyen B.J., Magan G.A., \& Boucher J.P. Anticipatory locomotor adjustments for avoiding visible, fixed obstacles of varying proximity. Human Movement Science 12: 259-272, 1993

McFadyen B.J. Malouin F. \& Dumas F. Anticipatory locomotor control for obstacle avoidance in mid-childhood aged children. Gait \& Posture 13(1): 7-16, 2001

McGraw M.B. From reflex to muscular control in the assumption of an erect posture and ambulation in the human infant. Child Development 3: 291-297, 1932

McGraw M.B. The neuromuscular maturation of the human infants. Nature 232: 403-404, 1943

McKenzie N.C. \& Brown L.A. Obstacle negotiation kinematics: age-dependent effects of postural threat. Gait \& Posture 19: 226-234, 2004 
Mohagheghi A.A., Moraes B., \& Patla A.E. The effects of distant and on-line visual information on the control of approach phase and step over an obstacle during locomotion. Experimental Brain Research 155: 459-468, 2004

Nasher L.M. \& Woollacott M.H. The organization of rapid postural adjustments of standing humans: an experimental conceptual model. In: Talbot RE, Humphrey Dr (Eds) Posture and Movement. Raven Press, New York, 243-257 pp, 1979

Nashner L.M. Computerized dynamic posturography. In: Joel A Goebel: Practical Management of Dizzy Patient. Lippicott Williams \& Wilkins. Philadelphia, 143-170 $p p, 2001$

Oeffinger D.J., Augsburger M.S., \& Cupp T. Pediatric kinetics: age related changes in ablebodied populations. Gait and Posture 5: 155-156, 1997

Ogg H.L. Measuring and evaluating the gait patterns of children. Physical Therapy 43: $717-$ 720,1966

Ornitz E.M. The functional neuroanatomy infantile autism. International Journal of Neuroscience 19: 85-124, 1983

Patla A.E., Prentice S., \& Robinson, C. Visual control of locomotion: strategies for clearing obstacles. Paper presented at International Society for Biomechanics Conference, Los Angeles, 1989

Patla A. E., Prentice S. D., Robinson C., \& Neufeld J. Visual control of locomotion: strategies fro changing direction and for going over obstacle. Journal of Experimental Psychology 17: 603-634, 1991

Patla A.E. \& Rietdyk S. Visual control of limb trajectory over obstacles during locomotion: effect of obstacle height and width. Gait \& Posture 1: 45-60, 1993

Patla A.E. \& Prentice S.D. The role of active forces and intersegmental dynamics in the control of limb trajectory over obstacles during locomotion in humans. Experimental Brain Research 106: 605-622, 1995 
Patla A.E., Prentice S.D. \& Gobb L.T. Visual control of obstacle avoidance during locomotion: Strategies in young children, young and older adults. In: A. M. Fernandez and N. Teasdale (Eds.), changes in sensorimotor behavior in aging, 1996

Patla A.E., Rietdyk S., Martin C. \& Prentice S. Locomotion patterns of the leading and trailing limbs as solid and fragile obstacles are stepped over: some insights into the role of vision during locomotion. Journal of Motor Behavior 28: 35-47, 1996

Patla A.E. \& Vickers J.N. Where and when do we look as we approach and step over an obstacle in the travel path? NeuroReport 8: 3661-3665, 1997

Paulus W.M., Straube A. \& Brandt T. Visual stabilization of posture. Brain 107: 1143-1163, 1984

Phillips S.J. \& Clark J.E. Infants' first unassisted walking steps: relationship to speed. Biomechanics X-A: 425-428, 1985

Piaget J. \& Inhelder B. The child's conception of space. London : Routledge and Kegan Paul Ltd., 1971

Pryde M.K., Roy A.E., \& Patla A.E. Age-related trends in locomotor ability and obstacle avoidance. Human Movement Sciences 16: 507-519, 1997

Rietdyk, S. \& Patla, A.E. Does the step length requirement in the subsequent step influence the strategies used for step length regulation in the current step? Human Movement Science 13: 109-127, 1994

Shirley M.M. The first two years. Vol I. Postural and locomotor development. Mineapolis: The University of Mineapolis Press, 1931

Sparrow W.A., Shinlfield A.J., Chow S., \& Begg R. K. Characteristics of gait in stepping over obstacles. Human Movement Sciences (15): 605-622, 1996

Spaulding S.J. \& Patla A.E. Obstacle avoidance during locomotion: effect of obstacle shape on gait modifications. IBRO World Congress of Neuroscience 3, 1991 
Statham L. \& Murray M.P. Early walking patterns of normal children. Clinical Orthopaedics and Related Research 79: 8-24, 1971

Sutherland D.H., Cooper L. \& Daniel D. The role of the ankle plantar flexors in normal walking. The Journal of Bone and Joint Surgery 62: 336-354, 1980

Sutherland D.H., Olsen R.A., Biden E.N., \& Wyatt M.P. The development of mature walking. London, Mackeith Press, 1988

Sutherland D.H. The development of mature gait. Gait and Posture 6: 163-170, 1997

Sveistrup H. \& Woollacott M.H. Longitudinal development of the automatic postural response in infants. Journal of Motor Behavior 28: 58-70, 1996

Sveistrup H. \& Woollacott M.H. Practice modifies the developing automatic postural response. Experimental Brain Research 114: 33-43, 1997

Taga G. A model of the neuro-musculo-skeletal system for anticipatory adjustment of human locomotion during obstacle avoidance. Biological Cybernetics 78: 9-17, 1998

Tinetti M.E. \& Speechley M. Prevention of falls among the elderly. The New England Journal of Medicine 320: 1055-1059, 1989

Thelen E., Fisher D.M., Ridley-Johnson R., \& Griffin N.J. Effects of body build and arousal on newborn infant stepping. Developmental Psychobiology 15: 447-453, 1982

Thelen E. Development origins of motor coordination: leg movements in human infants. Developmental Psychobiology 18: 1-22, 1985

Thelen E. Treadmill-elicited stepping in seven-month-old infants. Child development 57: 1498-1506, 1986

Thelen E., Ulrich B.D., \& Jensen J.L. The developmental origin of locomotion. In M. Woollacott \& A Shumway-Cook (Eds.), The development of posture and gait across lifespan, 25-47 pp, Columbia: University of South Carolina Press, 1989 
Thelen E. \& Ulrich B.D. Hidden skills: a dynamic systems analysis of treadmill stepping during the first year. Monographs of the Society for Research in Child Development 56 Serial 223, 1991

Ulrich B.D. Development of stepping patterns in human infants: a dynamical systems perspective. Journal of Motor Behavior 21: 392-408, 1989

Vallis L.A. \& MacFadyen B.J. Locomotor adjustments for circumvention of obstacle in the travel path. Experimental Brain Research 152: 409-414, 2003

Vallis L.A. \& MacFadyen B.J. Children use different anticipatory control strategies that adults to circumvent an obstacle in the travel path. Experimental Brain Research 167: 119-127, 2005

von Hosfsten C. Perspective control: a basic aspect of action development. Human Development 36: 253-270, 1993

Winter D.A. Biomechanics of normal and pathological gait: implications for understanding human motor control. Journal of Motor Behavior 21: 337-356, 1989

Winter D.A. Biomechanics and Motor Control of Human Movement. 2ndEdit. John Wiley \& Sons Inc. 1990

Witherington D.C., von Hofsten C., Rosander K., Robinette A., Woollacott M.H., \& Bertenthal B. The development of anticipatory postural adjustments in infancy. Infancy 3: 495-517, 2002

Zattara M. \& Bouisset S. Posturo-kinetic organisation during the early phase of voluntary upper limb movement. Journal of Neurology, Neurosurgery \& Psychiatry 51: 956965, 1988 
Appendix A 
Table 5. Unobstructed Gait Characteristics

\begin{tabular}{|c|c|c|c|c|c|c|c|}
\hline $\begin{array}{c}\text { Subject } \\
\#\end{array}$ & $\begin{array}{c}\text { Months } \\
\text { Walking }\end{array}$ & $\begin{array}{c}\text { Strides } \\
\text { analyzed }\end{array}$ & $\begin{array}{c}\text { Steps } \\
\text { analyzed }\end{array}$ & $\begin{array}{c}\text { Walking } \\
\text { Speed } \\
(\mathrm{m} / \mathrm{s})\end{array}$ & $\begin{array}{c}\text { Stride } \\
\text { length } \\
(\mathbf{m})\end{array}$ & $\begin{array}{c}\text { Stride } \\
\text { width } \\
(\mathbf{m})\end{array}$ & $\begin{array}{c}\text { Step } \\
\text { length } \\
(\mathbf{m})\end{array}$ \\
\hline 1 & 1 & 22 & 27 & 0.454 & $\begin{array}{c}0.321 \pm \\
0.073\end{array}$ & $\begin{array}{c}0.15 \pm \\
0.019\end{array}$ & $\begin{array}{c}0.158 \pm \\
0.046\end{array}$ \\
\hline 2 & 2.5 & 16 & 5 & 0.509 & $\begin{array}{c}0.335 \pm \\
0.051\end{array}$ & $\begin{array}{c}0.144 \pm \\
0.015\end{array}$ & $\begin{array}{c}0.1615 \pm \\
0.0315\end{array}$ \\
\hline 3 & 3 & 26 & 31 & 0.574 & $\begin{array}{c}0.404 \pm \\
1.136\end{array}$ & $\begin{array}{c}0.142 \pm \\
0.014\end{array}$ & $\begin{array}{c}0.202 \pm \\
0.068\end{array}$ \\
\hline 4 & 3.5 & 29 & 33 & 0.62 & $\begin{array}{c}0.445 \pm \\
0.130\end{array}$ & $\begin{array}{c}0.109 \pm \\
0.025\end{array}$ & $\begin{array}{c}0.2225 \pm \\
0.0705\end{array}$ \\
\hline 5 & 4 & 24 & 29 & 0.659 & $\begin{array}{c}0.445 \pm \\
0.083\end{array}$ & $\begin{array}{c}0.103 \pm \\
0.023\end{array}$ & $\begin{array}{c}0.225 \pm \\
0.048\end{array}$ \\
\hline 6 & 5 & 20 & 25 & 0.66 & $\begin{array}{c}0.46 \pm \\
0.083\end{array}$ & $\begin{array}{c}0.121 \pm \\
0.018\end{array}$ & $\begin{array}{c}0.2265 \pm \\
0.0575\end{array}$ \\
\hline 7 & 7.5 & 18 & 23 & 0.657 & $\begin{array}{c}0.508 \pm \\
0.089\end{array}$ & $\begin{array}{c}0.14 \pm \\
0.036\end{array}$ & $\begin{array}{c}0.2555 \pm \\
0.0515\end{array}$ \\
\hline 8 & 8 & 13 & 18 & 0.995 & $\begin{array}{c}0.612 \pm \\
0.067\end{array}$ & $\begin{array}{c}0.46 \pm \\
0.013\end{array}$ & $\begin{array}{c}0.301 \pm \\
0.0425\end{array}$ \\
\hline
\end{tabular}


Appendix B 
Table 6. Time-distance Parameters

\begin{tabular}{|c|c|c|c|c|c|c|}
\hline $\begin{array}{l}\text { Literature } \\
\text { Derived }\end{array}$ & $\begin{array}{l}\text { Independent } \\
\text { walking }\end{array}$ & $\begin{array}{c}\text { Walking } \\
\text { Speed } \\
\text { (m/s) }\end{array}$ & $\begin{array}{c}\text { Stride } \\
\text { Width } \\
\text { (m) }\end{array}$ & $\begin{array}{l}\text { Step Width } \\
\text { (m) }\end{array}$ & $\begin{array}{c}\text { Stride } \\
\text { Length } \\
(\mathrm{m})\end{array}$ & $\begin{array}{c}\text { Step } \\
\text { Length } \\
\text { (m) }\end{array}$ \\
\hline \multirow{2}{*}{$\begin{array}{c}\text { Bril \& } \\
\text { Breniere } \\
\text { (1992) }\end{array}$} & Onset & $0.28 \pm 0.09$ & & $0.23 \pm 0.034$ & & $0.103 \pm 0.029$ \\
\hline & 2 years & $0.77 \pm 0.25$ & & $0.111 \pm 0.033$ & & $0.342 \pm 0.065$ \\
\hline \multirow{2}{*}{$\begin{array}{l}\text { Sutherland } \\
\text { (1997) }\end{array}$} & Onset & $\begin{array}{l}\approx 0.60 \pm 0.28 \\
\text { (extracted } \\
\text { from graph) }\end{array}$ & & & $\begin{array}{c}\approx 0.43 \pm 0.13 \\
\text { (extracted } \\
\text { from graph) }\end{array}$ & \\
\hline & 1 year & $\begin{array}{c}\approx 0.74 \pm 0.30 \\
(\text { extracted } \\
\text { from graph) }\end{array}$ & & & $\begin{array}{c}\approx \approx 0.56 \pm 0.10 \\
\text { (extracted } \\
\text { from graph) }\end{array}$ & \\
\hline \multirow{2}{*}{ Present Study } & 1month & 0.454 & 0.103 & & 0.321 & 0.158 \\
\hline & 8 months & 0.995 & 0.46 & & 0.612 & 0.301 \\
\hline
\end{tabular}

Table 6. Data from the experimental cohort are compared with those from published reports of previous IW studies (Bril \& Breniere, 1992; Sutherland, 1997). 
Appendix C 


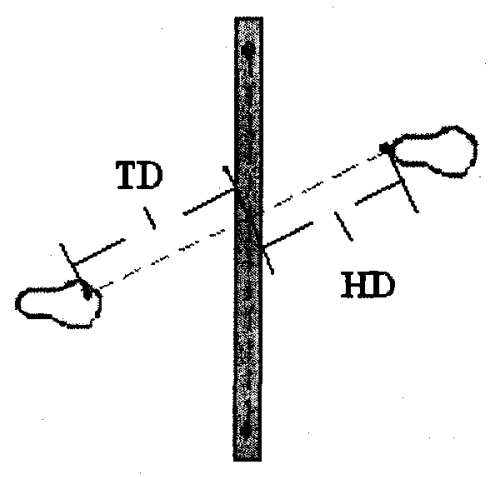

\section{Figure 8. Top View of the Walkway}

The top view of the walkway while the obstacle is crossed. The crossing point is indicated in red between two imaginary lines. TD (pre-obstacle distance) is toe to crossing point distance at toe-off prior to the obstacle in one step. HD (post-obstacle distance) is crossing point to heel distance at heel contact after the obstacle in the same step. 
Appendix D 


\section{Université d'Ottawa University of Ottawa \\ Service de subientions de recherche et deontologie Research Graats and Ethics Sernces}

December 20, 2006

Heidi Sveistrup

School of Rehabilitation Sciences

University of Ottawa
D. Gordon E. Robertson

School of Human Kinetics

University of Ottawa

Li Zhang

Object: Locomotor Adjustments Made by Toddlers while Stepping Over Obstacles (file H 05-04-05)

Dear Professors Sveistrup and Robertson and Ms. Zhang,

You will find enclosed the Health Sciences and Science Research Ethics Board renewal certification for your research project above-mentioned.

During the course of the study, any modifications to the protocol or forms may not be initiated without prior written approval from the REB. You must also promptly report to the REB all adverse events or experiences encountered by participants.

The renewal certification is retroactive to September 16,2006 and valid until September 16 , 2007. Please submit an annual status report to the Protocol Officer in September, 2007 to either close the file or request a renewal of ethics approval. This document can be found at: http/:www rges uottawa.ca'ethicsiapplication_dwn.asp

A copy of this renewal approval will be sent to Research Services, if necessary.

Please do not hesitate to contact me at extension

if you should have any questions.

Sincerely,

Rita D'Alessandro

Protocol Officer for Ethics in Research

For Dr. Daniel Lagarec, Chair of the Health

Sciences and Science REB 


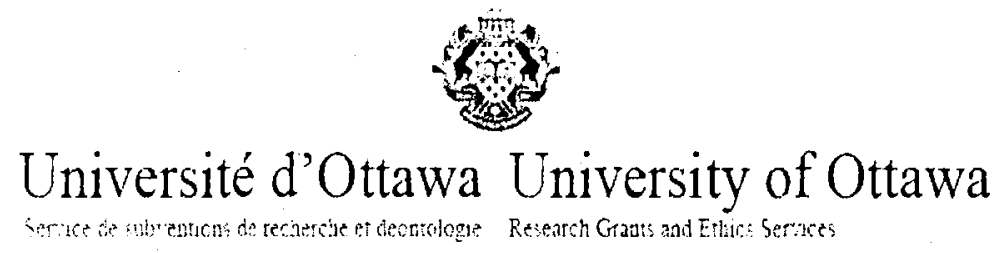

HEALTH SCIENCES AND SCIENCE RESEARCH ETHICS BOARD

CERTIFICATION OF ETHICS APPROTAL

This is to certify that the University of Ottawa Health Sciences and Science Research Ethics Board (REB) examined the application for extension of ethics approval for the research project Locomotor Adjustments Made by Toddlers while Stepping Over Obstacles (file $\mathrm{H} \mathrm{05-04-05)}$ ) submitted by Li Zhang and supervised by Heidi Sveistrup of the School of Rebabilitation Sciences and D. Gordon E. Robertson of the School of Human Kinetics. This project received initial ethics approval on September 16, 2004 and an extension on September 16. 2005 by the REB as meeting appropriate ethical standards set out in the Tri-Council Policy Statement and in the Procedures of the University of Ottawa Research Ethics Boards. The University of Ottawa REB members accordingly gave it a one-year extension of ethics approval. This ethics renewal certification is retroactive to September 16, 2006 and ralid until September 16, 2007.

Rita D'Alessandro

Desember 20.2006

Protocol Officer for Ethics in Research

Date

For Dr. Daniel Lagarec, Chair of the

Health Sciences and Science REB 